Portland State University

PDXScholar

5-9-1978

\title{
A Comparative Study of the Expressive Preposition Usage of Educable Mentally Retarded Children and Normals
}

Marie Deon Shope

Portland State University

Follow this and additional works at: https://pdxscholar.library.pdx.edu/open_access_etds

Part of the Mental and Social Health Commons, and the Speech Pathology and Audiology Commons Let us know how access to this document benefits you.

Recommended Citation

Shope, Marie Deon, "A Comparative Study of the Expressive Preposition Usage of Educable Mentally Retarded Children and Normals" (1978). Dissertations and Theses. Paper 2837.

https://doi.org/10.15760/etd.2831

This Thesis is brought to you for free and open access. It has been accepted for inclusion in Dissertations and Theses by an authorized administrator of PDXScholar. Please contact us if we can make this document more accessible: pdxscholar@pdx.edu. 
AN ABSTRACT OF THE THESIS OF Marie Deon Shope for the Master of Science in Speech Communication with emphasis in Speech Pathology/Audiology presented May 9, 1978.

Title: A Comparative Study of the Expressive Preposition Usage of Educable Mentally Retarded Children and Normals.

APPROVED BY MEMBERS OF THE THESIS COMMITTEE:
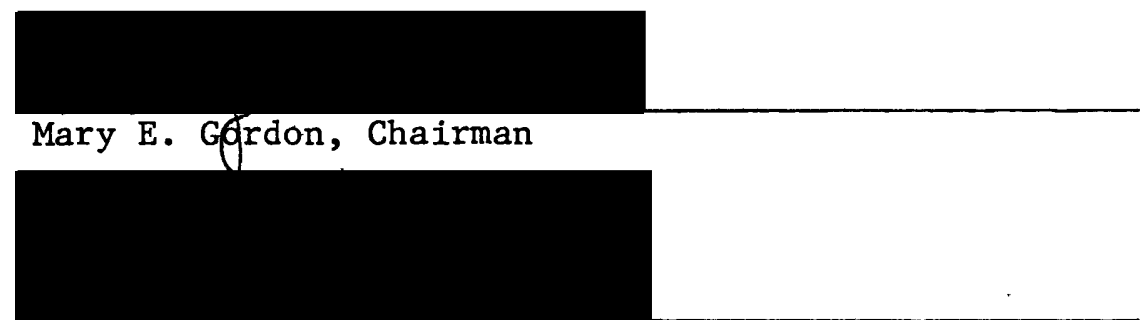

Robert L. Caftéel

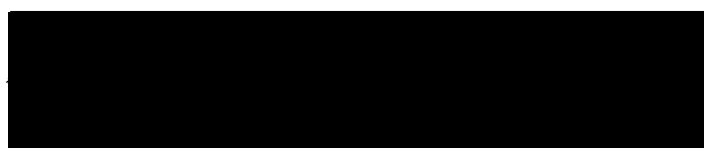

Georgiediustead

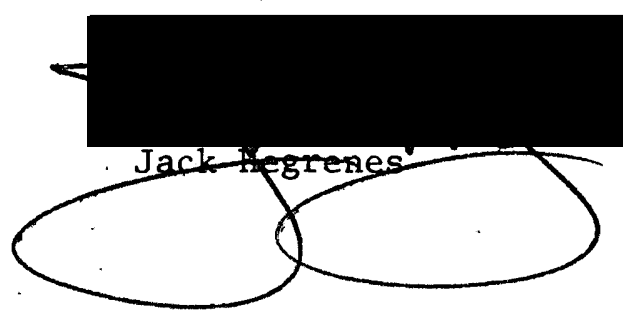

The importance of successful usage of prepositions to the social, communicative, and academic achievement of the school age child has been documented in the 1iterature. Information on language skills of educable mentally retarded (EMR) children is of special concern because they represent the sub-group of mentally deficient individuals most likely to interact and participate in academic settings and community life. 
The purpose of this study was to investigate which of 26 prepositions are acquired expressively by educable mentally retarded children. This study was designed to determine if there was a significant difference between the number of prepositions expressed by an EMR sample and those expressed by normals of similar mental age, and if the same prepositions were used by the two groups at given mental ages. The correlation between chronological age and the number of prepositions expressed by the EMR population was also investigated.

Thirty-two subjects in two mental age groupings participated in this study. At mental age six years ( \pm three months), eight EMR subjects and eight normals were selected. Eight individuals also comprised both groups at mental age eight years ( \pm three months). The Hustead Expressive Preposition Test, (HEPT) (Hustead, 1978) was administered to all subjects.

Results showed no statistically significant difference between the EMR and normal groups at either mental age in the number of prepositions expressed, $1 . e .$, the EMR students generally were found to express the same number of prepositions as normals of similar mental ages. A moderate correlation between chronological age and the number of prepositions expressed by the EMR subjects was evident, suggesting experience and maturation could be related to the number of prepositions expressed; however, this relationship could be attributed in part to the older mental age of the children of older chronological age.

Comparison of the prepositions used by both groups at mental ages six and eight years revealed more similarities than differences. Generally, the same prepositions were used by the subjects in the control and EMR groups at each mental age. Prepositions were found to develop 
similarly in number and type for both groups. Results of this study thus tend to indicate a "developmental lag" in usage of prepositions rather than a qualitative or disordered development. 
A COMPARATIVE STUDY OF THE EXPRESSSIVE PREPOSITION USAGE OF EDUCABLE MENTALLY RETARDED CHIIDREN AND NORMALS

by

MARIE DEON SHOPE

A thesis submitted in partial fulfillment of the requirements for the degree of

MASTER OF SCIENCE

in

SPEECH COMMUNICATION WITH EMPHASIS IN

SPEECH PATHOLOGY/AUDIOLOGY

Portland State University

1978 
TO THE OFFICE OF GRADUATE STUDIES AND RESEARCH:

The members of the Committee approve the thesis of Marie Deon Shope presented May 9, 1978.

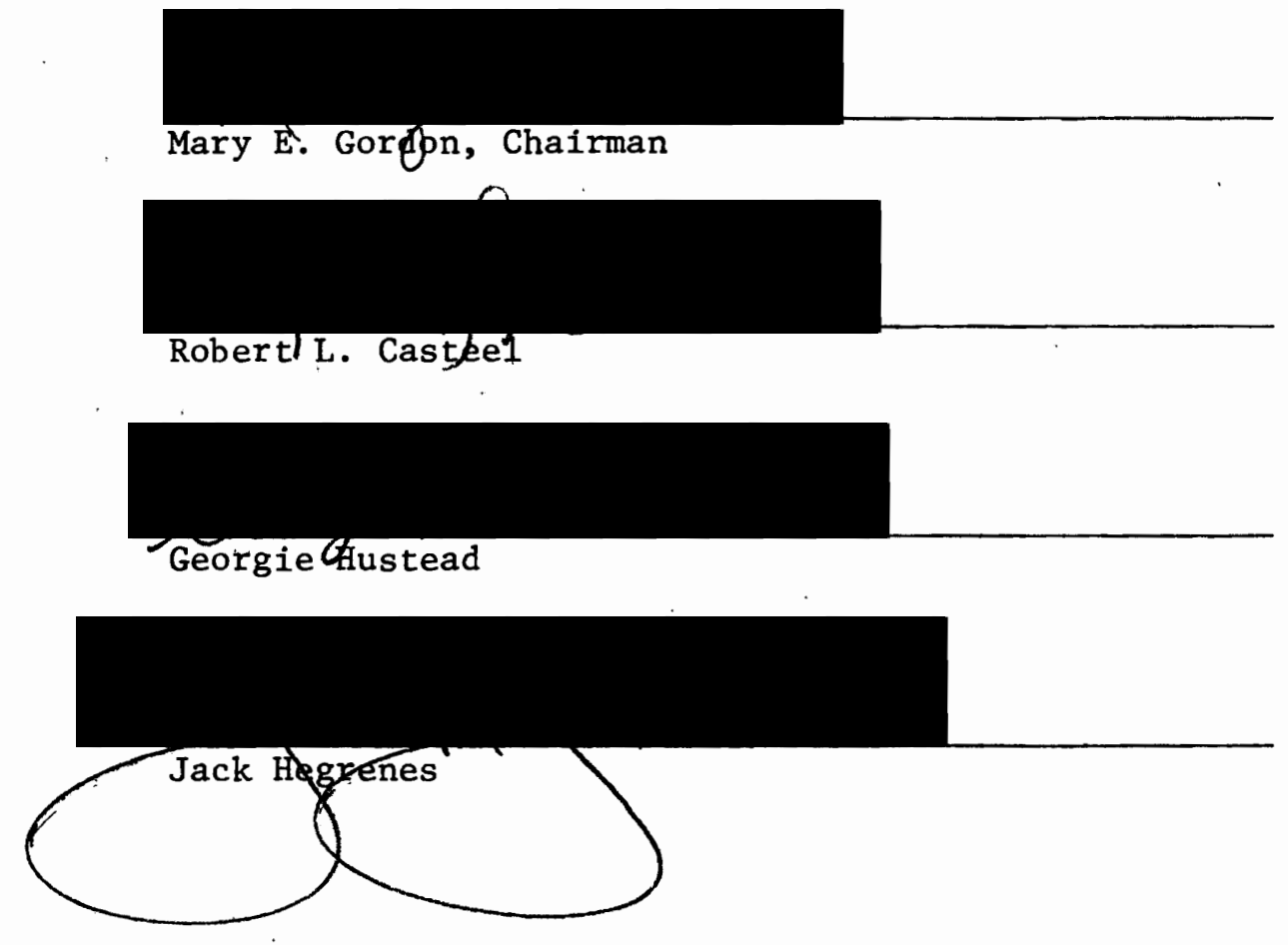

APPROVED:

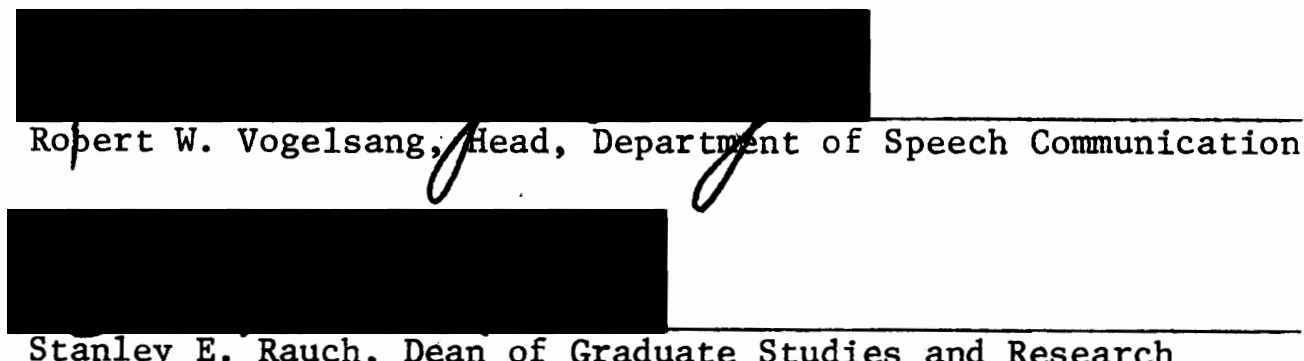

Stanley E. Rauch, Dean of Graduate Studies and Research 


\section{ACKNOWLEDGEMENTS}

I take this opportunity to express my appreeiation to all those who helped make the completion of this work a reality. Foremost are the members of my thesis committee. My personal thanks go to Mary Gordon, my chairwoman and long suffering advisor of six years, who unselfishly devoted hours of her time providing encouragement, and correcting and revising manuscript. Her never ending patience, willingness to help, and continual smile through all phases of this project was truly inspirational. I'm sure her relief at seeing me complete this project is surpassed only by mine, and is sweetened by the absence of my name on her daily appointment calendar. To Dr. Robert Casteel, I extend my thanks for his assistance, particularly in the initial formulation of this research. His sharing of "wit and wisdom" in the area of language development was greatly appreciated. My thanks go to Georgie Hustead for sharing her expertise. in the area of prepositions, for training me on her test, and for surrounding me with empathy and encouragement. I also express, with thanks, my appreciation to $\mathrm{Dr}$. Jack Hegrenes, both for his participation on my committee and for his assistance in making the statistical analysis of this study an enjoyable experience.

My gratitude and appreciation goes to all the administrators, teachers and secretaries, too many to mention individually here, in schools in Hillsboro, McMinnville, Sherwood and Tigard. Without their liberal cooperation; this research would not have been possible. 
Special appreciation is extended to my parents, Dan and Sophia Johnson, for their constant support and encouragement, and for 1istening at the right times. Finally, I want to convey my deepest love and appreciation to my dear husband, Stan, for all his patient support, consideration, and feigned interest throughout the running of this study: 
TABLE OF CONTENTS

PAGE

ACKNOWLEDGEMENTS • • • • • . • • • • • • • • • • • • • •

LIST OF TABLES

LIST OF FIGURES

viii

CHAPTER

I

INTRODUCTION

Statement of Purpose

Definitions . . . . . . . . . . . . . .

II REVIEW OF THE LITERATURE . . . . . . . . . . . . 6

Development of Prepositions . . . . . . . 6

Language of the Mentally Retarded . . . . . .

Variables Affecting Language

Development

Language of the Retarded

Rationale for Language Intervention . . . . . .

III METHODS

Subjects . . . . . . . . . . . . . • •

Evaluation Instruments . . . . . . . . . .

Evaluation Procedures . . . . . . . . . . .

Data Analysis . . . . . . . . . . . . . 34

IV RESULTS AND DISCUSSION . . . . . . . . . . . . 35

Results . . . . . . . . . . . . . . 35

Discussion . . . . . . . . . . . . . 
CHAPTER

V SUMMARY AND IMPLICATIONS . . . . . . . . . . . 47

Summary ................ 47

Implications :. . . . . . . . . . . . 49

SELECTED BIBLIOGRAPHY . . . . . . . . . . . . . . . . . 52

APPENDICES

A Normative Data on Prepositions . . . . . . . . . 59

B Sentences Used to Elicit the Twenty-six

Prepositions (Hustead, 1974) . . . . • • •

C Number of Children at Each Age Level that

Correctly Expressed the Individual

Prepositions . . . . . . . . . . . . .

D Sentences Used to Elicit the Fourteen

Prepositions (Heckel, 1975) . . . . . . . .

E Number of Prepositions Correctly Expressed

at Each Age Level (Heckel, 1975) . . . . . . 69

F Parent Permission Form . . . . . . . . . . 70

G Hustead Expressive Preposition Test

(Hustead, 1978) . . . . . . . . . . .

Score for Each Subject... . . . . . . . . 


\section{LIST OF TABLES}

\section{TABLE}

PAGE

I Mann Whitney $U$ and Probabilities for the

Two Mental Age Groups . . . . . . . . . • •

II Chronological Age, Mental Age, and Preposition

Scores of EMR Subjects . . . . . . . . . . . 38

III Number of Children in Each Group Correctly

Using Each Preposition . . . . . . . . . •

IV Number of Preposition Omissions . . . . . . . . . . 


\section{LIST OF FIGURES}

FIGURE

PAGE

1 Range of Prepositions Expressed and Mean Score for Each Subject Group . . . . . . . . . . . . 


\section{CHAPTER I}

\section{INTRODUCTION AND STATEMENT OF PURPOSE}

\section{Introduction}

The great frequency and relative importance of prepositions in the English language have been reported by various researchers (Dewey, 1923; French, Carter, and Koenig, 1930; Pierce, 1969). Lillywhite (1958) stated prepositions begin to appear in the normally developing child's speech between the ages of three and four years, with more prepositions added between four and five years. Accordingly, successful usage of prepositions and other functor words is often used as an indication of a child's language refinement, yet surprisingly few tests of language development have examined more than three or four prepositions. Given the abundance and variety of prepositions cited in the literature, these tests could hardly be expected to detect minor deviations of usage in this area.

It has been demonstrated that speech and language difficulties of any nature can have debilitating effects upon a child's social and educational adjustment. (Bibey, 1951; Gens, 1951). Unfortunately, the effects of such difficulties initially may be unnoticed. Speaking about the academic difficulties of disadvantaged children, Berieter and Engelman (1966) stated that for a child to be successful in school, he should have the ability to use the prepositions "in," "on," "under," and "between," in describing arrangements of objects. 
Successful usage of prepositions could also be important to "special populations" as well. As the subgroup of mentally deficient individuals most likely to interact and participate in community life, educable mentally retarded (EMR) children are of special concern. Possessing potentialities for minimal social and occupational achievement, these children may learn academic subjects through the second to sixth grade level (Kirk, 1972). They will attend classes, socialize, and eventually join the work force. Jordan (1967) has stated this presents a need ". . . for information concerning the language abilities required for satisfactory adjustment in the various situations in which the mentally retarded individual will be placed." Unfortunately, the amount of available research in this area is inadequate.

While some information regarding expressive preposition usage of normally developing children is available, the literature on expressive language abilities of the retarded individual has been concerned chiefly with the evaluation of speech skills (McCarthy, 1964). This reviewer found only two studies which have mentioned preposition usage and/or development in EMR children. Utilizing an oral-response test adapted from the "action-agent" test in the Merrill Palmer Scale of Mental Tests, Sievers and Essa (1961) found prepositions to increase in number with mental age in trainable mentally retarded (TMR) subjects. Blount (1970) investigated the responses of non-organic EMR subjects to a test battery of 32 concepts including 8 prepositions. A "developmental lag" in usage of all concepts was noted. This limited research does not provide a complete picture of prepositional usage or development by EMR children. It is easy to recognize the applicability of Jordan's (1967) statement: ". . linguistic studies of retarded persons have been slighted and our 
grasp of the facts is less than complete."

It has been generally assumed, though not substantiated, that mentally retarded individuals acquire all language concepts, including prepositions, in the same order and manner as normally developing children $x$ but at a slower rate (Semme1, Barritt, Bennett, and Perfetti, 1968; Yoder and Miller, 1971). These of ten unchallenged statements lead to the usage of standards and methods of preposition instruction which have been effective with normal children, but which may not be applicable to the needs of an EMR population. More definitive information regarding expressive preposition acquisition and usage by EMR children is needed to assist speech pathologists and other educators in planning appropriate programs and methods of instruction for this special population.

\section{Statement of Purpose}

The purpose of this study was to investigate which prepositions are acquired expressively by educable mentally retarded children. More specifically, this study sought to determine which of twenty-six prepositions as measured by the revised Hustead Expressive Preposition Test (Hustead, 1978) are expressed by EMR children at mental ages of six years ( \pm three months) to eight years ( \pm three months) when compared to normals of matched mental age.

This study purported to answer the following questions:

1. Do EMR children demonstrate significant differences in the number of prepositions expressed when compared to normal subjects of similar mental ages?

2. Is there a correlation between chronological age of the EMR children and the number of prepositions expressed? 
3. Do the EMR subjects express the same prepositions as the normals of similar mental ages?

\section{Definitions}

The following definitions are provided in order to clarify the terminology used in this review of the literature. This list is not exhaustive, but these terms are the most common ones appearing in current literature concerning language development in mentally retarded individuals.

Educable Mentally Retarded: Kirk (1972) describes the educable mentally retarded child as one, who because of subnormal mental development, is unable to profit sufficiently from the program of the regular elementary school, but who is considered to have potentialities for development in the following areas: 1) educability in academic subjects of the school at a minimum level; 2) educability in social adjustment to a point where he can get along independently in the community; 3) minimal occupational adequacies to such a degree that he can later support himself partially or totally at the adult level. Though intelligence quotient (IQ) is not the sole determiner in diagnosis, an IQ score two to three standard deviations below the mean (approximately 50 to 69 ) is a prime determiner (Grossman, 1973).

Mental Retardation: Mental retardation refers to significantly subaverage general intellectual functioning existing concurrently with deficits in adaptive behavior, and manifested during the developmental period (Grossman, 1973).

Morphology: The study of and rules for forming morphemes, the smallest meaningful grammatical unit, into words. Morphemes may be classified as roots or affixes (Wiig and Seme1, 1976).

Phonology: The specification of units of sounds which compose words and other forms in 1anguage (Carroll, 1964).

Semantics: The specification of the meanings of linguistic forms and the syntactical patterns in relation to objects, events, processes, attributes and relationships in linguistic experience (Carro11, 1964).

Syntax: The specification of patterns in which linguistic forms may be arranged and the ways in which these patterns may be modified or transformed in varying contexts (Carroll, 1964). 
Trainable Mentally Retarded: Kirk (1972) described the trainable mentally retarded child as one who is not educable in the sense of academic achievement, social adjustment, independence in the community, or independent occupational adjustment at the adult level. However, he does have potentialities for learning the following: 1) self-help skills; 2) social adjustment in the family and in the neighborhood; 3) economic usefulness at home, in a residential school, or in a sheltered workshop. An IQ score three standard deviations below the mean (35-50) is often used as one determiner in diagnosis (Grossman, 1973). 


\section{CHAPTER II}

\section{REVIEW OF THE LITERATURE}

This review of the literature relative to preposition usage by educable mentally retarded (EMR) children encompasses three areas of research. First, basic principles and definitions of prepositions and the acquisition process are discussed. This is followed by an outline of the language research and maturational levels of EMR children. The final section, the rationale for speech pathology involvement in program planning for these children, demonstrates the need for research of linguistic skills of EMR children.

\section{Development of Prepositions}

Linguists have recognized four basic aspects of language: phonology, morphology, syntax, and semantics. The grammatical part of speech termed "prepositions" are classified under the heading of morphology. The individual units of morphology, morphemes, are the smallest meaningful language elements and may be classified in a variety of ways. Brown (1965) differentiated between "free" morphemes (such as "cat," "to," and "hat") which have meaning standing alone, and "bound" morphemes which do not stand alone, but modify the meaning of free morphemes in an "inflection" or "derivation." Examples of bound morphemes include the markers for pluralization (s,z,es), the prefix "un," and the suffix "1y."

Morphemes also may be divided into major and minor components (Voegelin, 1957; Pierce, 1963 and 1969). Major morphemes are considered 
the information components of language, such as nouns and verbs, and are essentially "free." Minor morphemes are the "little" words or parts of words which are less important to the meaning of the sentence or phrase. They may be bound or unbound (free). Minor morphemes are said to be the essentially grammatical elements of language (Pierce, 1969).

These terms, i.e., major morphemes and minor morphemes, are generally synonomous with the terms "contentives" and "functors." Grammatical morphemes or functors are said to play a less than essential role when compared to contentives. Rather than providing the semantic meaning as contentives do, they serve to modify the meaning. Functors are few in number but high in frequency of occurrence in the English language.

It is generally thought functors are not necessary parts of language for sentence comprehension; however, results of studies comparing children's understanding of telegraphic and normal sentences showed children's comprehension of normal speech to be better than that of telegraphic speech (Shipley, Smith, and Gleitman, 1969). It has been found that children's earliest verbal utterances appear to be contentive in nature, consisting of concrete nouns and action verbs. Certain semantically less complex adjectives, prepositions and pronouns follow. Generally, auxillaries, determiners and markers are missing from these early utterances (Stremel and Waryas, 1974). As functors rarely appear in isolation, their acquisition appears to be related to the growth in the length of utterances (Brown, 1973; Erwin-Tripp, 1973).

Prepositions may be defined as functors or minor morphemes. Since they may stand alone, they are considered "free" or "unbound" minor morphemes (Pierce, 1963). Traditionally, prepositions have been defined as words that show relationships between their objects and some other word 
in the sentence. As such, linguists have cited only four simple or "pure" prepositions: "from," "of," "after," and "for" (Pierce, 1969). These relational words do not have tangible referents because instead of naming objects, they name relations between objects or between events. Often words labeled prepositions, label properties that are variable and tend to be assessed relative to some standard which itself also may vary, e.g., "under" and "in front of" (Clark, 1973). Other morphemes labeled as prepositions are not always followed by objects and are used in varying manners within the sentence structure. Pierce (1969), in viewing all minor morphemes, expressed a desire to see additional research which would lead to the redefining of the group of minor morphemes arbitrarily classified in the preposition category:

Utilizing a more broadly based definition, Carroll (1964) considered the term "prepositionals" to be one of the six major form class components in English. The conceptual meaning for this class, consisting of prepositions and prepositional phrases, includes relations of spatial, temporal or logical positions relative to nominals. Grimm (1975) expanded the definition by describing prepositions as ". . .morphologically, invariant factors which serve to express relations of the locative, temporal, modal, and causal type." Clark (1973), in a detailed account of the spatial-perceptual skills precluding preposition development, analyzed prepositions in terms of referential dimensions. Thus "directional" or "locative prepositions" ("at," "onto," "in," "to," "into," "from," "out of," "via," "across," "through") may be said to indicate punctual location. Relational prepositions ("above," "below," "ahead," "behind," "over", "under," "in front of," "in back of," "ahead," "behind," "before," "after") also indicate location, but do so by 
specifying a direction from the point of reference in which the object is located (Grimm, 1975).

Such categorizations. of prepositions do not suggest that a given preposition would fit into only one category. The multiplicity of meanings of prepositions has been noted by several researchers (Fries, 1952; Jesperson, 1969; Friedman and Seely, 1976). Streng (1972) 1isted 60 simple prepositions and 25 compound prepositions which she believes represent those in common use in English today. of these, 9 are used $90 \%$ of the time, with an average of 36.5 possible different meanings for each one. Grimm (1975), in his investigation of the spontaneously produced prepositional phrases of German preschoolers and first graders, categorized many of the locative prepositions analyzed as temporal as we11. Ambiguous prepositions, such as those capable of both locative and temporal meäning, compound prepositions ("at about"), and phrasal prepositions ("in agreement with") often contribute to the language/learning disordered child's confusion with prepositions (Montague, Jenson, and Wepman, 1973; Friedman and Seely, 1976).

Minor morphemes or functor words have grammatical meaning, that is, meaning concerned with the constructions in which they are found or to which they may be applied. Traditionally, they are viewed as functioning as purely structural signals (Gleason, 1961). Some grammarians contend only contentives (nouns, verbs) may have lexical meaning in reference to states of affairs outside the utterance or text in which they are found. However, Carroll (1964) stated many function words, such as the prepositions of "in," "on," "with," and "despite," have lexical components which are relatively easy to define. 
That some prepositions contain both syntactical and lexical meaning gives more credence to their significance in language. As such, they contribute to expression of abstract levels of thinking and subtle relationships. As Lee (1959) stated:

Without the little words "if," "so," "even," "whether," "for," "any," and "about," one loses the grammatical constructions in which abstract thoughts are symbolized in English, the modifiers, the dependent clauses, the prepositional phrases. Without the word "if," how can you talk or think in terms of probabilities? Without the word "when," how can you make plans for the future? How can you see an orderly sequence of events without the words "before," "after," "during," "while," "since," "soon," and "late."

The ability to express abstractions is but one example of the importance of prepositions. Their frequency of usage has also been well documented. The group of minor morphemes (including prepositions) occur five times as frequently as major morphemes. This is in contrast to the finding that 250 minor morphemes may be found in Webster's 4th New Collegiate Dictionary (1961), while several thousand major morphemes are listed (Pierce, 1969).

Researchers monitoring telephone conversations and analyzing the relative frequency of words spoken, discovered five minor parts of speech (auxiliary verbs, pronouns, prepositions, conjunctions, and articles) comprised only 5 percent of the different words used, but 57 percent of all the spoken words (French et al., 1930). Of the total words analyzed, 12,400 were prepositions and conjunctions. Dewey (1923) analyzed 100,000 words of connected written material to illustrate the relative frequency of every word, and found that of the first 100 words which occurred over 100 times in the written material, 10 were prepositions. Fries (1940) found 9 prepositions accounted for over 90 percent of the prepositions used in a large body of written material. These include in order of 
frequency: "of," "in," "to," "for," "at," "on," "from," "with," and "by." It is evident from this research that although the percentage of different prepositions is small in comparison to other word classes, their relative frequency of usage is proportionately high. In a more recent study, Jones, Goodman, and Wepman (1963) analyzed the speech of 12 normal adult English speakers. Of 34,801 words obtained, 452 occurred at a rate of at least 20 occurrences per 100,000. Thirty-one prepositions constituting 11 percent of all words used, were included in this list.

The frequency of preposition usage in young children's speech does not correlate to that of adult speech, however. It is generally stated that prepositions occur late in the development of the child's language structure. During the early stages of the child's language development, prepositions are omitted, with their relational meaning implied, e.g., "doggie chair" for "doggie in chair" (Brown, 1973). Stern (1965) noted when the tendency to first use prepositions does appear, it grows far more rapidly than the power to discriminate one preposition from another. Thus substitution of one preposition for various others is commonly observed. His suggestion for a "prepositional universal" was based on the assumption that the child reduces many prepositional expressions to a general denominator which overrules all others. The universal's selection is a product of chance. Similar views were held by Jespersen (1969) who described prepositions as "empty words" which are first learned as fixed components of whole phrases which can be isolated and freely combined only later as members of a proper word class.

This idea of "chance" or learning of prepositions as a "whole" class was refuted by Grimm (1975) for three reasons. First, frequency counts of prepositions have been conducted (Cazden, 1971) and the establishment 
of a close correspondence between the frequency of prepositions in parental speech and the frequency of acquisition and correct preposition usage has been substantiated. Secondly, it has been found that prepositions which occur frequently are also those which can be used variously. Grimm's last rebuttal stemmed from findings that the frequency of acquisition of locatives corresponds to the development of spatial concepts. Grimm thus supported Slobin's (1966) contention that prepositions are obtained a few at a time rather than as an entire class.

The specific nature of preposition development has been variously analyzed. Grimm's (1975) study of the spontaneously produced prepositional phrases of preschoolers and first graders, lead to hypothesized rules for acquisition of prepositions which also apply to acquisition of other word classes. Grimm's first finding was that word meaning developed from concrete to abstract. This is supported by Werner and Kaplan's (1963) statement". . .particles such as prepositions, conjunctions. - appear initially as concrete in content, both etymologically and ontogentically." The finding that prepositions are acquired in order of place, then manner and time supports this contention (Menyuk, 1971; Grimm, 1975), for it is the more overt or noticeable functions which are learned first.

At the beginning of language development, locative relations are expressed without prepositions. Substitutions may also be evident, e.g., "she wants to stay at the puppy". (Menyuk, 1971). Grimm (1975) found older children replace complex prepositions with simple ones or with combinations of prepositions (e.g. "to hop into fence" for "over the fence" and "to come in in" for "to come through door"). Menyuk (1971) suggested the children's absence or incorrect usage of prepositions could 
result from difficulty in selecting the correct prepositions to denote conditions of place, manner, and time in specific situations. At later ages, one finds an elaboration of words to provide finer definition of the prepositions available to the child (e.g. "he gets all the way close" for "almost near"). The more grammatical inflections or prepositions, those key to structural design, prove to be more complex in that they are either partially or fully disregarded for a long time and are not readily demonstrated by action alone.

The more complex prepositions are usually those less frequently used as we11. Berieter and Engelman (1966) suggested that in casual conversation, it is easy for children to escape learning prepositions for, along with conjunctions, they occur in situations where the context makes precise understanding of them unnecessary. Brown and Bellugi (1964) explained omissions of prepositions to be due to the "unstressed nature" of functor words in the English language. The heavy stressing is placed on contentives, the words carrying the meaning of the utterance. Brown and Bellugi made another plausible suggestion. Since nouns, verbs, and adjectives are words that make reference, they are easily demonstrated by parents, and are the kinds of words children have been encouraged to practice speaking.

The second general rule hypothesized by Grimm was that semantically simpler words are acquired before semantically complex words. Grimm (1975) stated it is possible to make limited predictions about the acquisition sequence of words by describing the structure of single words in defined "wordfields.". Along this line, Clark's (1973) semantic feature theory maintained word meaning may be divided into semantic features which correspond to fundamental perception categories of space and time. 
He maintained the words with fewer features will normally be learned firșt (complexity hypothesis). Young children learning words gradually add features from general to specific or in order of hierarchical dependence. The complexity hypothesis also predicts the spontaneous appearance of spatial terms before temporal terms.

More specifically, Clark stated that in autonomous pairs, the positive member (the simpler), should be acquired before the negative. The notion was that the positive members specify the assumed or known direction or relation, and the negative member specifies its direction or relation by negating the assumed one. Considering the pair "into" and "out of," "into" is the positive term, for the normal direction is toward the denoted object or referent, and "out of" (the negative) specifies its direction of motion by negating the assumed direction, away from the referent. Similarly in the pair "in front of" and "behind," "in front of" is considered positive because it points out the presence of something rather than its absence. "Behind" is negative since it describes the area out of sight. In 1971, Clark investigated the acquisition of the relational terms "before" and "after" to determine if "before," considered the positive term of the pair, was acquired first. Results of this and other studies supported the hypothesis that the positive member of a preposition pair is acquired before the negative member (Grimm, 1975; Johnson, 1975).

The first appearance of prepositions has been variously dated, although there is consensus on their late appearance in the child's language corpus. Lillywhite (1958) found the first prepositions to appear in the children's speech between three and four years. Stern (1965) collected data relative to the ages at which children first use prepositions 
and found the earliest appearance at one year, ten months with an average of two years, three months. Menyuk (1969) cited the appearance of prepositions in children's speech at two to three years. Several tests have included items which examine preposition acquisition and expression and comprehension. The Houston Test for Language Development (Crabtree, 1958), the C.C.D. Language Manual (University of Oregon Medical School, 1958), the Denver Developmental Screening Test (Frankenburg and Dodds, 1967), the Developmental Age Study (Baker and Dudry, 1968), and the Sequenced Inventory of Communication Development (Hedrick and Prather, 1970) list comprehension and expression of prepositions by chronological age (see Appendix A). The Utah Test of Language Development (Mecham, Jex, and Jones, 1969) tests comprehension of "in," and "by," for children between the ages of two and three years. The Daberon (Danzer, Gerber, and Lyons, 1972) tests understanding of "in," "under," "behind," "on," "In front of," and "next to" for three year olds. The Boehm Test of Basic Concepts (Boehm, 1969) examines the comprehension of prepositions "through," "next to," "inside," "around," "over," "between," "behind," "after," "below," and "above" in kindergarten and first and second grade children.

Hustead (1974) developed the Expressive Preposition Test (EPT). Her study of expressive acquisition of 26 prepositions acquired from four through nine years of age, revealed a high correlation between chronological age and ability to express prepositions (see Appendices B and C). Heckel (1975) examined preposition acquisition in children 18-42 months, using the Revised Expressive Preposition Test (REPT) which contained 14 of the original 26 prepositions (see Appendices D and E). Results showed expressive prepositions tend to be acquired at different age levels, with 
each age level using a proportionately greater number of prepositions.

\section{Language of the Mentally Retarded}

In the preceding section, the importance of prepositions relative to frequency of usage and function in expressing higher order abstractions was discussed. The importance of skillful usage of prepositions is not limited to normally developing children. Special populations, such as the educable mentally retarded children who will take an active part in community life, need these skills as well. Since language skills and intellectual ability have been found to be intimately related, an interesting question, posed by Newfield and Schlanger (1968), is whether any differences or similarities in language acquisition or development can generally be predicted for normal and retarded children. The following is a review of literature pertinent to just such a question regarding preposition development.

\section{Variables Affecting Language Development}

In recent years, the adjustment difficulties of individuals with handicapping conditions have evoked renewed concern. Interest, in turn, has been focused on providing these individuals with the appropriate instruction and/or training needed for successful social and occupational adjustment. The importance of language skills to meet this objective cannot be overly stressed. Various studies have demonstrated that "language deficiencies" in the form of speech defects occur in the retarded child (Gens, 1951; Karlin and Strazzula, 1952; Spreen, 1965; Schiefelbusch, 1969). Only recently, however, have studies examined the linguistic skills of mentally retarded populations. 
Documentation of language deficiencies in EMR children has been presented by various researchers (Karlin and Strazzula, 1952; Ogland, 1972; Harrison, Budoff, and Greenburg, 1975). It has been noted EMR children are often separated from the general school population and referred and eventually placed in an EMR classroom, on the basis of a verbal expressive deficit (Ogland, 1972; Harrison, et al., 1975).

As in normal language development, it is generally assumed that intelligence is but one factor affecting speech and language development in retarded individuals (Smith, 1971). The general assumption is made, however, that the higher the intellectual endowment of retarded children, the better their language ability (Karlin and Strazzula, 1952; Jordan, 1966). Incidence statistics suggest a high correlation between intelligence level and language development. In a review of available literature, Spreen (1965) .found 100 percent incidence of language disturbances in children in IQ's below 20, 90 percent in children with IQs between 21 and 50, and 45 percent in the moderately retarded. The interdependence of language and intelligence makes the effects of each difficult to separate. Often, measures of language performance and comprehension are used as measures of intelligence. Harrison et al. (1975) stated in U.S. schools, verbal facility is usually the factor upon which IQ is heavily based. Along this line, the finding of declining intelligence with age in Down's Syndrome children on the Standford-Binet was theorized as demonstrating attention to deficiencies in language and concept formation (Cornwal1, 1974).

Intelligence alone is not an accurate measure of prognosis for language development. Lenneberg, Nichols, and Rosberger (1964) stated there is a significant relationship between maturation and language development 
as well. Rosenberg (1970) found language development in any child has been found to be more influenced by maturational factors than by IQ. Jordan (1966) found a fairly high incidence of language disorders demonstrated for several years among the mildly retarded, but found maturity to operate as a source of improvement. Spreen's 1965 review, cited three studies supporting this view. In these studies EMR populations were found to have a higher vocabularly size than normals of matched mental age, thus indicating chronolgical age and experience had some effect in development.

Environmental effects also have been discussed in relation to the language capabilities of retarded individuals. The effects of one such influence, that of institutionalization, is of ten difficult to determine for most of the institutional children also are those with the most severely depressed IQ. Accordingly, Spreen (1965) cited several studies which found language deficits to increase with length of institutionalization, and these children performed more poorly on language tests than did children of similar intelligence reared at home. Statistics indicate 57 to 72 percent of institutionalized retardates have speech defects (Spradlin, 1963; Keane, 1972). Some of the effects of environment on learning are well documented in McCarthy's (1964) account which demonstrated children from a restricted environment, though retarded in all areas of development, demonstrated the greatest retardation in language skills. However, in a study comparing the usage of 13 parts of speech of 10 institutionalized and 10 noninstitutionalized children, it was found that only in the category of preposition usage was the non-institutionalized group favored. Degree and type of usage for all other parts of speech were similar between the two groups (Montague et al., 1973). It 
was hypothesized that deprivation in experience caused disorientation to concepts of time and place basic to preposition usage.

Spradlin (1963) suggested that an examination of the effects of institutionalization on children is not uni-faceted but multi-faceted; other factors often are confounded with the environmental variables under investigation. Various explanations for the language defects of institutionalized mental defectives included: de-emphasis of normal processes of family stimulation, disruption of mother-child relationships, separation from family, lack of privacy, and lack of speech motivation (Schlanger, 1953; Jordan, 1967).

The trauma of institutionalization is but one environmental influence capable of affecting linguistic development. In a study of the maternal linguistic environment to which young normal and Down's Syndrome children were exposed, it was found that retarded children received more simplified linguistic models (Buium, Rynders, and Turnure, 1974). There was evidence mothers of retarded children used a higher incidence of grammatically incomplete sentences and one word responses. An examination of the extent to which the early linguistic environment was related to later characteristics of the language of retarded children, revealed no definitive conclusions but indicated a need for further research in this area.

\section{Language of the Retarded}

In viewing language abilities and disabilities of retarded children, most authors agree no special type of language deficit appears to be characteristic of the mental defective (Spreen, 1965). The classification "retarded language development" is frequently applied as a general 
term covering the range of language dysfunctions. These dysfunctions include all the types of speech and language impairments found in normal and clinical group children. Reaffirming Spreen's clarification, Keane (1972), in a review of available literature, found no unique configuration or patterns of speech and language problems to be demonstrated in the mentally retarded as a group or within any subcategory. Jordan's (1966) description of the mentally retarded as a "heterogenious population" may be thus applied to their language skills as well. Karlin and Strazzula (1952) found much individual variation in the severely retarded children they studied; some could converse with adults, some had better vocabulary, etcetera. Generally, there is a need for more specific information regarding full language capabilities of the retarded. There have been no comprehensive studies of the total range of language deficits in mentally retarded populations, for most researchers have focused primarily on articulation deficits (Spradlin, 1963).

If mentally retarded individuals comprise a "heterogenous population" in terms of language abilities, there is no configuration of specific language characteristics common to each individual. Rather, specific language characteristics, as mentioned here, are those specific skills or lack of skills which have been in evidence in some groups of retarded individuals and may or may not be present in others: Researchers have found evidence of the following in the language of the mentally retarded: 1) limited vocabulary (Molloy, 1961; Carroll, 1964; Jordan, 1966; Strazzula, 1966; Henderson, 1971; Harrison et a1., 1975); 2) comprehension skilis exceeding expressive skills (Sievers and Essa, 1961; Strazzula, 1966; Cornwa11, 1974; Naremore and Dever, 1975); 3) delay of onset of speech and language development (Karlin and Strazzula, 
1952; McCarthy, 1964; Jordan, 1966); 4) syntax and morphological skills below age expectations (Brown and Berko, 1960; Menyuk, 1964; Palermo, and Jenkins, 1964); 5) significantly lower levels of performance in skills of categorization and concept usage (Stephens, 1963; Blount, 1967); 6) limited ability to use abstract language (Karlin and Strazzula, 1952; Strazzula, 1966; Jordan, 1967); and 7) general developmental lags in language development and/or disordered language development (Wewetzer, 1959; Spreen, 1965; Semmel et al., 1968). These latter two findings limited usage of abstract language and developmental lag versus disordered development, will be discussed more fully as they relate to preposition development of EMR children.

Predominance of Concrete over Abstract Language. Retarded individuals limited ability to abstract has been cited by several researchers. Cornwal1 (1974) noted severe limitations in abstractions and higher level integrative ability in the mentally deficient population he investigated. To fully understand the impact of these statements, a definition of concreteness and abstraction is warranted. Of these two terms Lewin (1935) wrote:

Concreteness of thinking and acting (in the feeble minded) signifies chiefly that every object and event derives its meaning in a peculiarly high degree from the present situation--that it is not a separable part of the situation..... abstraction, by which one generally means construction of groups according to certain factual relations of the individual objects, is rendered more difficult.

Brown (1958) theorized that concreteness or a concrete mind would operate with subordinate categories such as nouns, and an abstract mind with superordinate categories such as articles, action, quality and relation. The implications of such a statement to preposition development in retarded individuals may best be emphasized in view of past contentions 
that some minor morphemes are more abstract than others. Lee's (1959) discussion of Korzybski's (1958) levels of abstraction, the Structural Differential, shows how the parts of speech can be classified on a continuum from the concrete to the abstract.

The first level is called the "event level" (I) and represents the silent world which exists outside the organism. Next is the "object level" (II). which is the nonverbal image of the world that the nervous system makes up out of the details it selects from the first level. The third level of "verbal, level" (III) is the world of words. In the first part of this level ( $\operatorname{III}_{1}$ ), one finds individual names, proper nouns and names for single objects and particular people. The next sublevel (III 2 ) represents a more abstract naming process whereby the child learns terms which disregard individual differences such as "lady," "man," "dog," etcetera. Verbs, which are labels for actions, also are categorized here. The child must go beyond a simple naming phase to perceive similarity between such different activities as "open the door," and "open your eyes." Leve! III $_{3}$ is a higher level of verbal abstraction in which the child categorizes several types of objects and designates them by one word. Examples include inclusion of "coat," "shoe," and "hat" into the category "clothing." Level IV is called the "inferential level" and refers to the ability to anticipate past and future events in a particular point in time. Level $\mathrm{V}$ represents various levels of abstraction termed higher order abstractions. At this level, Lee (1959) included prepositions, conjunctions and pronouns. Perhaps the more concrete or easily demonstratable prepositions such as "in," and "on," could be placed at level III, while the more abstract terms such as "about" and "toward" are not found until level V. The importance of these words was 
stressed again by Lee: ". . . these little words are maps for a host of subtle relationships and high order abstractions. They are the means by which perceptual experiences are structured and ordered in our particular linguistic patterns."

If EMR children have difficulty abstracting, they may have subsequent difficulty using prepositions correctly. Unfortunately the available information on preposition usage by EMR children is negligible. Sievers and Essa (1961) found increasing usage of pronouns, verbs, and prepositions with advancing mental age of retardates, while the proportion of nouns decreased. In a study examining institutionalized retardates performance on the Assessment of Children's Language Competency Test (ACLC), it was found that verbs and prepositions (higher order abstractions, according to Lee) were better understood in multi-element presentations than in isolation, while modifiers and nouns were better understood in isolation (Delp and Smeets, 1973). These few studies and examinations of other studies on abstraction abilities of retarded individuals do not necessarily contend the development in language expression in the retarded child is different from that of normal children. In reviewing literature, however, Spreen (1965) found in many cases the development of the ability to abstract lags behind that of normally developing children of comparable age.

Qualitative Versus Quantitative Theories. References to the qualitative versus quantitative theory of language development in retarded individuals have been made previously. The debate centers on whether the retarded child's development is different in form and manner (qualitative difference) from the normally developing child, or whether it follows the order of the normal child's development, but at a slower rate 
(quantitative difference).

Evidence for a qualitative or disordered difference stems from various sources. Generally, Ogland (1972) found language behavior of children in special classes to be below expectation according to mental age. As early as 1959, Wewetzer formulated the hypothesis that brain damaged children do not simply have less of the ability of their normal peers, but that the structure of their performance is different. Semmel et a1., (1968) suggested mentally retarded children are less capable of performing abstract mental operations required to generalize grammatical patterns. In investigating the development of English morphological inflections in educationally subnormal (ESN) special school children, Love11 and Bradbury (1967) found ESN children between the ages of 14 and 15 did less well than normal first graders. Besides qualitative or disordered development in language skills, it was also noted that in physical development, the mentally retarded child does not just exhibit a "developmental 1ag." He has different sucking and swallowing patterns, coos differently than normal children and does not play with the sounds he produces (Molloy, 1961).

The theory of developmental lag or quantitative differences in language development has much support in the literature. Spreen (1965) noted several studies have indicated a lag of development in retardates in such measures as sentence length, sentence complexity, discrimination of speech sounds, and percentage of nouns used. More specifically, increasing usage of pronouns, verbs, and prepositions with mental age in both institutionalized and noninstitutionalized retardates has been noted (Sievers and Essa, 1961). Lackner (1968) analyzed the language performance samples from retarded children and suggested that the language 
behavior of normal and retarded children are not qualitatively different. He found both groups to follow similar developmental trends, but the most severely retarded children became arrested in their development and remained at lower levels of oral language acquisition. In a study of concept usage of retardates, Stephens (1963) attributed the significantly lower levels of performance in skills of category and concept usage to be indicative of at least a developmental lag. In consideration of this research, the need for individual examination of language concepts and skills is evident.

Perhaps Yoder and Miller's (1971) suggestion for both a developmental delay and qualitative difference existing in the language of the retarded is the most viable. Research of the acquisition of individual language area skills by mentally retarded individuals is needed. Naremore and Dever (1975) related well the importance of such information:

If the mentally retarded child is developing the same kind of language as the normal child, only at a slower rate, than the clinician could appropriately behave as if the child were normal, simply slowing the introduction of new language building materials. However, if the mentally retarded child's development is different than normal children (qualitative difference) then the teachers behavior must take this into account.

\section{Rationale for Language Intervention}

Traditionally, a pessimistic view of the value of speech management with mentally retarded populations has been held (Jordan, 1967); however, more recent research and philosophies have supported language intervention. With the advent of P.L. 94-142 (1975), which guarantees a "free, appropriate education" for all children in the last restrictive environment, more special children will be receiving speech and language instruction. 
The high incidence of speech problems which exists in this population in comparison to children with higher IQ's has been used as support for equivocally increased amounts of speech management (Scofield, 1972). Bibey (1951) contended that optimal function can be expected as a result of developing capacity, for both the mentally deficient and normal child. This, in part, is the key to their inclusion in speech improvement programs. These children will in the future be economically useful and socially adjusted. Corrected speech can make a difference in some cases (Scofield, 1972). Willis and Garrison (1970), in analyzing stories told by EMR and normal adolescents, stressed the importance of teaching communication skills. To maintain the educable person in the community, it appears an emphasis on building a varied speaking vocabulary and skills for conversation would be both necessary and rewarding.

Reviewing programs and research conducted with language in mentally deficient individuals, Scofield (1972) constructed basic considerations regarding the necessity of language programs for EMR children, including:

1) EMR children will use oral communication for almost all of their expressive and receptive needs throughout their life times.

2) Self concept is vitally affected by adequate speech skills.

3) Good human relations are based on communication skills.

4) Vocative adaption and future adjustment are vitally connected to ability in oral communication.

With the emphasis on adaptation in the community, self-sufficiency is vital. Since verbal communication skills play a paramount role in achievement of this goal, the need for speech and language intervention programs for the retarded should be obvious (Keane, 1972). In planning goals, specific objectives should be directed toward the establishment 
of a continuum for the progressive development of the child's potentialities (Strazzula, 1966). The clinician is concerned with how to best facilitate maximum language performance from the mentally retarded child. The answer depends heavily upon having a realistic conception of what language capabilities the retarded child has and what they should next learn (Naremore and Dever, 1975).

This conception of language capabilities must come from knowledge of language functioning. Unfortunately as Ogland (1972) stated, there is.". . a lack of more general types of descriptive language behavior of the mental retardate." To meet this end, various researchers have suggested further avenues and methods of investigation. Keane (1972) stated further research might be directed toward delineating the incidence and precise meaning nature of the language problems found in retarded persons. Schiefelbusch (1969) favored a break from traditional research designed to emphasize deficiency and instead to discover if language and communication skills can be taught effectively to retarded children. Although this belief is well founded, the basic knowledge of development is pre-requisite to teaching of any concepts. As Scheifelbusch (1969) later stated ". . we should know under what arrangements these skills are learned. What are the functional aspects of speech, language and communication that are requisite to learning?"

Various researchers have contended that certain areas of investigation warrant further study. Gens (1951) maintained that research, one of the three responsibilities of speech pathologists in the area of mental deficiency, could repeat much of the work completed with speech defective children of normal IQ and compare results obtained with mentally deficient individuals. Carroll (i964) urged that the slower process of 
acquisition be utilized as a measure for studying language processes. Hopefully, research as such would point to processes which tend to limit or facillitate language development in mentally retarded individuals and techniques for normals as well.

Whatever the emphasis, the task at hand is difficult. Schiefel- : busch, Copeland, and Smith (1967) stated in order to obtain information, the researcher must develop additional procedures for evaluation of language. Once the procedures are developed, language requirements within various situations and the degree to which these requirements are met by retarded children can be evaluated.

The general lack of an organized body of information on which to base highly developed training programs could possible be responsible in part for limited availability in the past, of services described by Schiefelbusch et a1. (1967). P.L. 94-142, however, does not allow trained professionals to avoid assuming responsibility for necessary instructional programs for the retarded. Research is needed to aid instructors of language to better serve these children. As Keane (1972) stated: this void in our knowledge needs to be satisfied so that forces may be marshalled more effectively to attack the basic communication problems of the mentally retarded." Elimination or reduction of the discrepancy between the retarded child's language skills and the language requirements of the community in which he will live should then be the goal of any language training program.

A review of the literature relevant to preposition acquisition of educable mentally retarded children stresses the importance of prepositions in the English language. Research on linguistic skills of educable mentally retarded children all but overlooks their acquisition and usage 
of prepositions. In order to plan appropriate program of language remediation, teachers, speech pathologists and other special educators need to know where the child is in terms of language capabilities and in what areas he should next receive instruction. In the case of EMR children, this information is particularly vital. If the development of a particular language area follows the similar order of a normal child, only at a slower rate, the instructor need only slow down the presentation of new word instruction materials. If, however, development is different, a modification of instruction methods and approaches is warrented.

To date, there have been no exhaustive studies examining preposition usage and development by EMR children. Data from such research could aid speech pathologists and other special educators in planning appropriate instructional programs. 


\section{CHAPTER III}

\section{METHODS}

\section{$\underline{\text { Subjects }}$}

\section{Description of Subjects}

This investigation was conducted with 32 subjects from two populations, educable mentally retarded children and children of normal intelligence. The experimental group consisted of 16 educable mentally retarded children from classrooms in Oregon public schools in Hillsboro, McMinnville, Sherwood and Tigard. The control groups consisted of 16 children of normal intelligence but similar mental ages, as the EMR group, from classrooms in Hillsboro and Tigard.

Initially, parents of prospective subjects were sent permission form letters explaining the nature and purpose of the investigation (Appendix F). Students with returned, signed permission forms were then screened for inclusion in this study. The two resultant samples were divided by mental age into four groups of children, consisting of a control and an experimental group at five years nine months to six years, three months; and a control and an experimental group at seven years, nine months to eight years, three months.

\section{Selection of Subjects}

Classification. Administrators and teachers were consulted to verify the diagnosị of educable mentally retarded (IQ 50-69) for the experimental group and normal intellectual functioning (IQ 90-109) for the 
contro1 group.

Hearing Acuity. Each subject passed a pure tone audiometric screening test administered bilaterally at $20 \mathrm{~dB}$ in the speech frequencies of $500,1,000,2,000$, and 4,000 $\mathrm{Hz}$.

Articulation and Speech Intelligibility. A brief sample of speech and articulation ability was obtained from each subject. Spontaneous speech was elicited by examiner questions regarding hobbies, and interests. Subjects not 100 percent intelligible, as judged by the examiner, were excluded from this investigation.

Mental Age. Mental Age was estimated by administration of the Slosson Intelligence Test (SIT) (Slosson, 1971).

Previous Language Training. Subjects who had previously received extensive one-to-one language intervention on prepositions were excluded from this investigation.

\section{Evaluation Instruments}

\section{Slosson Intelligence Test}

As an index of mental age, the Slosson Intelligence Test (SIT) was administered to all subjects. Adapted from items on the Stanford-Binet and the Gesell Developmental Scales, the SIT is a brief, individual test designed to be used by relatively untrained examiners. It consists of a series of developmentally designated questions and answers which emphasize language skills (Himelstein, 1972). Resultant test scores may be converted to both. MA and IQ equivalents. The SIT requires expressive responses as does the preposition test utilized in this investigation.

The SIT was standardized on 139 individuals from four to fifty years, living in both rural and urban areas in New York State. Back- 
grounds of the population varied, and only those who did not speak English were excluded. Published validity studies report correlations between the SIT and Wechsler Full Scale IQ's to range from .54 to .93, while correlations between the SIT and the Stanford-Binet reportedly run slightly higher in a range from .76 to .90 .

Results of test administration to EMR populatons revealed correlations between the SIT and the WISC Full, Verba1, and Performance IQ's as $.54, .85$, and .20 respectively. Correlations between the SIT and Stanford-Binet IQ's were .76 and of MA scores were .81. Although discredited as an initial measure of intelligence, the SIT was reported to be a fairly valid tool for intellectual screening or re-evaluation of primary age EMR children (Jongeword, 1969). Boyd (1978) stated the SIT was a respectable screening measure of IQ, when a full scale WISC could not be given. In this investigation, the SIT was used only to verify the school's diagnosis of EMR and normal and to estimate mental ages.

\section{Preposition Test}

A revised version of the Hustead Expressive Preposition Test (HEPT) (Hustead, 1978), was administered to each subject. In this test, the subject's verbal expression of 26 prepositions is tested by instructing the subject to explain where an object is located or to describe the examiner's activity. The Expressive Preposition Test (EPT) (Hustead, 1974) was first administered to six children at each age grouping of four, five, six, seven, eight, and nine years. Results of this study indicated a high correlation between the age of the children and their ability to express prepositions. Generally, each age group through the eight year old level verbalized a progressively higher percentage of 
prepositions. Heckel (1975) administered the Revised Preposition Test (REPT) to 12 children at each of the following age groups: eighteen months, twenty-four months, thirty months, thirty-six months, and fortytwo months. The same trend of progressively more prepositions acquired with age was noted.

Personal communication with the author of the EPT, revealed the test to be in the process of standardization. Twelve children at six month age groupings between two years and twelve years, six months will be tested. Recent test modifications include the exclusion of picture stimuli and the rewording of stimulus questions (see Appendix G for a complete listing of prepositions and the manner in which they were elicited).

\section{Evaluation Procedures}

Upon selection of the test population and matched controls, the Hustead Expressive Preposition Test (HEPT), as described above, was administered to each subject. Prior to test administration, the examiner engaged the child in casual conversation. Due to the verbal nature of this test, subjects were excluded from the study if the examiner did not succeed in establishing an immediate speaking relationship with them.

The children were tested individually in a familiar, quiet room at their school. They were seated opposited the researcher, who initially put them at ease by casual conversation. If the researcher did not establish a speaking relationship within a short period of time at the beginning of the interview, the child was not included in this study.

A11 supplies for testing were placed on the floor by the researcher. The visual stimuli for eliciting responses were presented individually. For example, when the researcher wanted to elicit the response "by," 
only a small toy car was placed by a box on the table, followed by the question "Where is the car?" to elicit the response "by."

If the child did not respond or if he requested a repetition of the stimulus, either verbally or by exhibiting a puzzled look on his face, the examiner repeated the stimulus up to three times. In the event that a wrong answer was given to the first item, the examiner stated: "Te11 me in a different way where the - - is." This probe was given on the first item only. If a wrong answer was given on any of the other 25 questions, the examiner counted it incorrect and asked the next question.

\section{Data Analysis}

All tests were administered and scored by this examiner. With one point allotted for each correct response and no points given for incorrect responses; a total of 26 points was possible. The Mann-Whitney $U$ test, the most useful alternative to the parametric $t$ test, was conducted to determine the significance of difference at .05 between mean number of prepositions expressed between the two groups, i.e., EMR and normal subjects. The correlation between chronological age and the number of prepositions expressed by EMR children was determined by using a Spearman Rank Correlation coefficient (rs). Actual prepositions expressed by the two groups were discussed and listed in chart form. 
CHAPTER IV

RESULTS AND DISCUSSION

\section{$\underline{\text { Results }}$}

The purpose of this.study was to investigate which of 26 prepositions are expressed by educable mentally retarded children (EMR) at the mental ages of six years $( \pm$ three months) and eight years ( \pm three months). Specifically, this study was designed to compare the preposition usage of two groups, EMR children and children of normal intelligence, at the above mental ages. The Hustead Expressive Preposition Test (HEPT), (Hustead, 1978), was administered to al1 subjects.

The first question posed was: Do EMR children demonstrate a significant difference in the number of prepositions expressed when compared to normal subjects of similar mental ages? The significance of difference in the number of prepositions expressed between the EMR and normal groups at each mental age grouping was determined utilizing the Mann-Whitney U. Table I shows that the difference between the experimental (EMR) and the control (normal) groups is not significant at the .05 level for either mental age grouping. The results indicate, therefore, that EMR children at both mental ages expressed a similar number of prepositions when compared with normals of similar mental ages.

This result is further shown by Figure 1 which illustrates the range of the number of prepositions and the mean for each group. Both the EMR groups demonstrated a slightly greater range. The EMR children 
TABLE I

MANN WHITNEY U AND PROBABILITIES FOR

THE TWO MENTAL AGE GROUPS

\begin{tabular}{lccccc}
\hline & \multicolumn{2}{c}{ Mean Scores } \\
\hline Mental Age & EMR & Normals & $\mathrm{U}$ & $\mathrm{P}$ \\
\hline 6 years & 15 & 16.2 & 20 & $.520 *$ \\
8 years & 17 & 17.8 & 29 & $.399 *$ \\
\hline
\end{tabular}

*not significant at the .05 level

at mental age six had a range of scores from 11 to 19 , while the range for the controls was 13. to 18. Similarly, the EMR children at mental age eight demonstrated a range of 13 to 20 correct responses as compared to the range of 15 to 20 for the normals. A slightly higher mean for the controls was also noted, although the difference is not statistically significant.

The second question in this investigation was: Is there a correlation between chronological age of the EMR children and the number of prepositions expressed? A positive correlation would imply maturation and experience via "time on earth" is related to growth in preposition usage. In Table II, preposition score as a function of chronological age and mental age is displayed. Computation of the Spearman Rank Correlation Coefficient revealed a $r_{s}$ of 0.536 , i.e., a moderate correlation between the chronological age of the EMR subjects and the number of prepositions expressed. This indicates that approximately 25 percent of the explained difference can be accounted for by this relationship. 
O - Experimental 6 years

D - Experimental 8 years

- Control 6 years

- Contro1 8 years

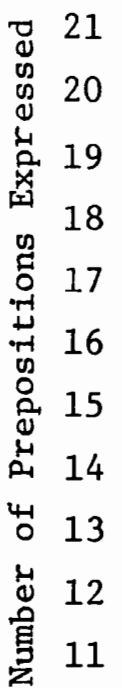


Age Grouping of Children by Mental Age

Figure 1. Range of prepositions expressed and mean score for each subject group.

The third question asked was: Do the EMR subjects express the same prepositions as normals of similar mental ages? Specifically, it was asked if there is a qualitative difference between the two groups in the order of prepositions expressively acquired. Table III displays the number of children in each group who expressed the individual prepositions. At mental age six years, all eight children in each group identified the following: "in," "under," "out of," "around," and "down." Additionally, all eight subjects in the control population identified "up," "with," "off," and all eight subjects in the EMR group used "on." No children in either group expressed "along" or "for."

At mental age eight, all children used the following prepositions: "in," "on," "up," "under," "out of," "around," and "down." Al1 the control groups also used "with," "off," "after," "in front," and "through." No children in the eight year groups used "along." 
TABLE II

CHRONOLOGICAL AGE, MENTAL AGE, AND PREPOSITIONS

SCORES OF EMR SUBJECTS

\begin{tabular}{|c|c|c|}
\hline $\begin{array}{l}\text { Chronological Age } \\
\text { Years - Months }\end{array}$ & $\begin{array}{l}\text { Mental Age } \\
\text { Years.Months }\end{array}$ & $\begin{array}{l}\text { Prepositions } \\
\text { Expressed }\end{array}$ \\
\hline 8.7 & 5.10 & 14 \\
\hline 9 & 6.2 & 15 \\
\hline 9 & 5.9 & 17 \\
\hline 10 & 5.9 & 11 \\
\hline 10.8 & 5.11 & 12 \\
\hline 11 & 6.3 & 14 \\
\hline 11.3 & 7.9 & 13 \\
\hline 11.5 & 7.9 & 17 \\
\hline 11.6 & 7.9 & 14 \\
\hline 12 & 6.3 & 19 \\
\hline 12 & 7.11 & 20 \\
\hline 12.1 & 6.2 & 19 \\
\hline 12.2 & 8 & 20 \\
\hline 12.6 & . & : 19 \\
\hline 12.9 & 8.1 & 13 \\
\hline 13.4 & 7.10 & 20 \\
\hline
\end{tabular}


TABLE III

NUMBER OF CHILDREN IN EACH GROUP CORRECTLY

USING EACH PREPOSITION

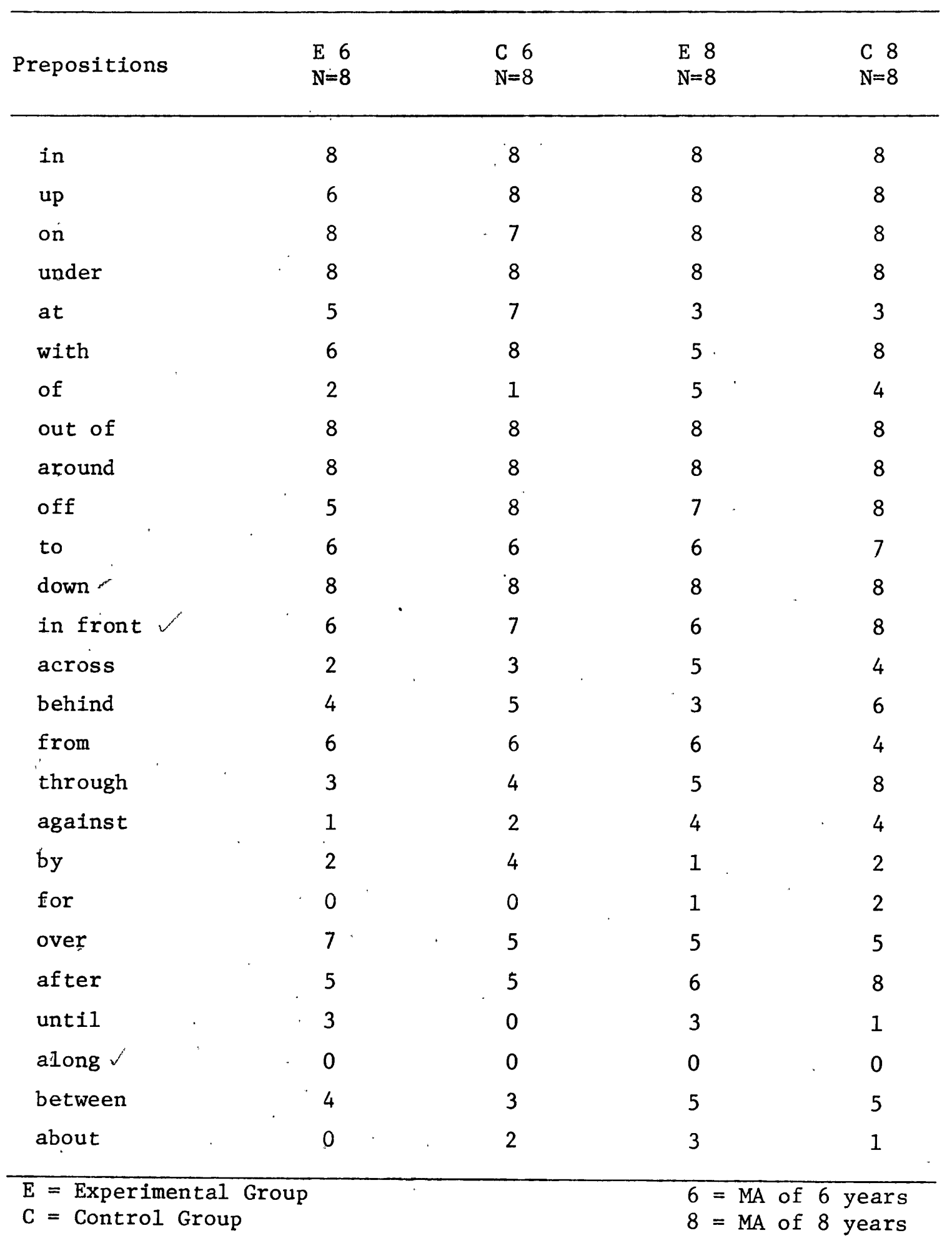


Growth trends were somewhat evident in comparing the mental age eight groups with the younger subjects. Not only was there an increase in the mean number of prepositions expressed for each child, but more children in each group expressed individual prepositions.

Examination of omissions of prepositions provides additional information regarding the nature of preposition development. Table IV Iists the prepositions which were omitted and the number of omissions for each group. The mental age six group omitted prepositions 16 times on 10 different prepositions, while the controls had 17 omissions on just 7 different prepositions. The prepositions "of" was the one most often omitted. The mental-age-eight experimental subjects had 16 omissions on 10 different prepositions, while the controls had 12 omissions on just 5 different prepositions. It is interesting to note that the tendency to omit prepositions decreased with mental age in the control group, but not in the experimental groups.

In addition to omitting prepositions, errors of substituting incorrect preposition or other words occurred in all groups. The mentalage-six experimental group substituted 63 while the controls of similar mental age used 57 substitutions. The experimental group showed a greater variety of substitutions of different prepositions (37) than did the controls (29). The controls responded with only three different out-of-class substitutions, i.e., substitutions of other parts of speech for prepositions. These included: "half/about," "last/after," and "not too full/about." The experimental group used seven different out-of-class substitutions, including: "Iittle bit/about," "almost/ about," "half/about," "low/about," "away/across," and "1ate/after." The experimental group showed two instances of immature, but developing 
TABLE IV

NUMBER OF PREPOSITION OMISSIONS

Prepositions

E 6

C 6

E 8

C 8

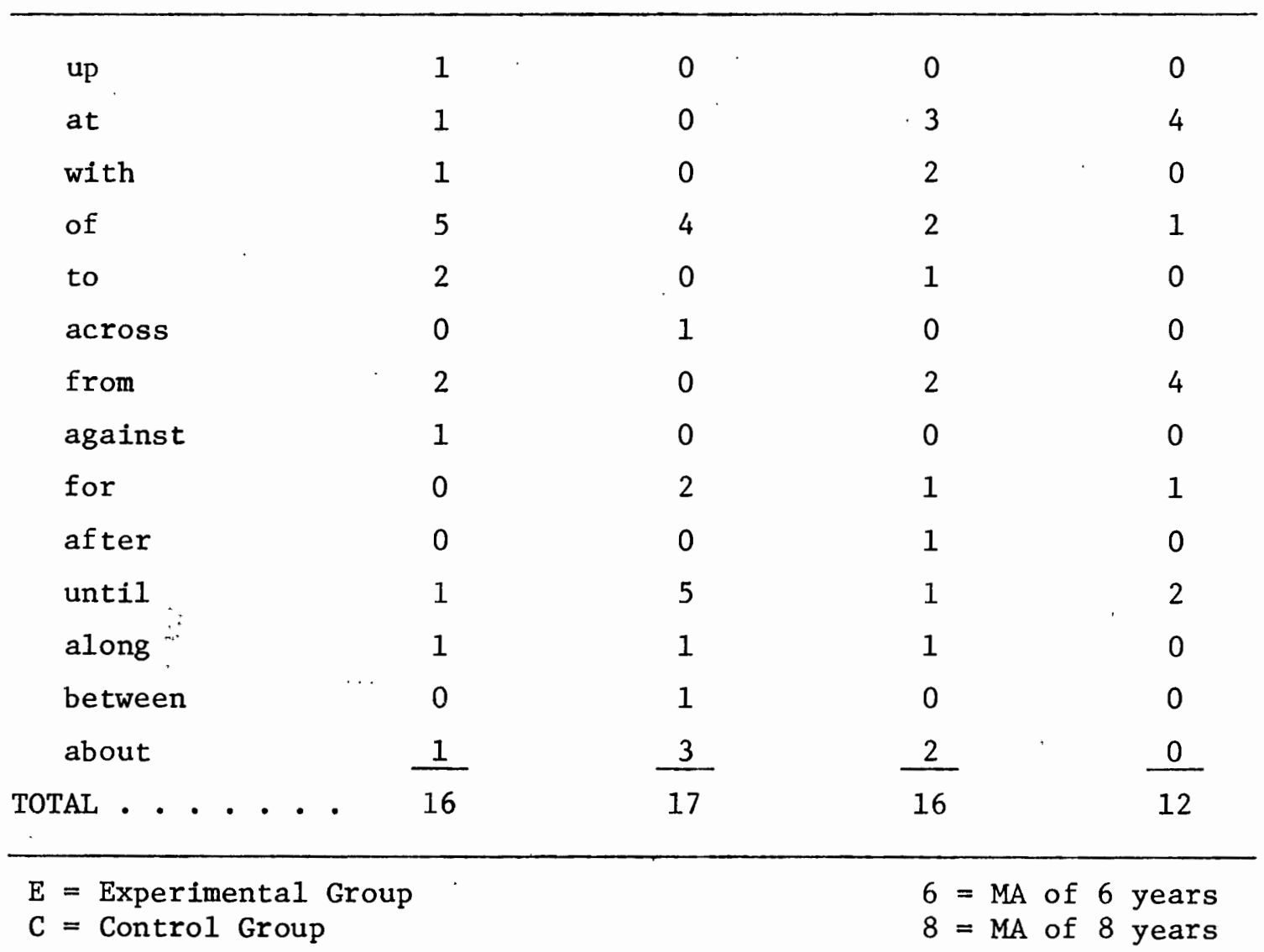

preposition approximation: "inhind" for "behind" and "intween" for "between." The most common substitutions were: "in back of/behind," "on/for," "from/for," "on/against," "on/along," "in/through," and "besides/by."

The older groups evidenced fewer substitutions. The mental-ageeight experimental subjects used 54 substitutions on 32 different prepositions and the controls used 45 substitutions on 31 different substitution combinations. Four out-of-class substitutions were noted 
for the experimental group: "away/across," "empty/about," "right here/ in front," and "half/about." The control group also used four: "almost/in front," "little bit full/about," "forward/along," and "end/ along." The most common substitutions were: "on/along," "in front/ across," "on/against," "from/for," "besides/by," "in back of/behind," and. "on/for." It can be seen that the older children used fewer substitutions, both in class and out-of-class, than the younger mental age group. The controls had slightly fewer substitutions than the experimentals in all prepositions.

\section{Discussion}

In viewing preposition usage| of educable mentally retarded children, several variables have been|considered. Some of these, chronological age and mental age in relation to preposition scores for each subject, are listed in Appendix $H$. By controlling the variable of mental age, statistical analysis of the difference between the number of prepositions expressed by EMR and normal children at mental ages six and eight years was completed. The performance difference was not significant at .05 level for either mental age group, indicating the EMR group expressed approximately the same number of prepositions as normals of similar mental ages. Although the difference in number of prepositions expressed was not significant, slight differences were noted in range of total scores and the mean number of prepositions expressed (FIgure 1). The wider range in number of prepositions expressed within the EMR groups is consistent with research reported in the 1iterature showing this group to be a more heterogeneous than homogeneous population. Findings of this study are in agreement with those 
of Sievers and Essa (1961) that the number of prepositions expressed increased with mental age in an educable mentally retarded population. At mental age six, the mean score was 15 and at mental age eight the mean score was 17 for this sample. It cannot be stated with any degree of certainty, that this relationship would appear consistently at all age levels, based solely on these results. Research using children of younger mental ages may find greater discrepancies in performance between an EMR and normal group.

The variable of chronological age was similarly considered within the limitations of this study. Statistical analysis revealed a moderate correlation between chronological age and the number of prepositions expressed by the EMR subjects, with approximately 25 percent of the explained difference attributable to experience and maturation. This would seem to contradict findings that EMR children express similar numbers of prepositions as normals of the same mental age. It must be mentioned, however, that since the 16 children involved in analysis were subjects taken from two different mental age groups, such a relationship is to be expected. Most of the children of younger chronological age were also the younger in mental age. Chronologically, the children in the mental-age-six group ranged from nine years to twelve years, one month, while the children in the mental age eight group ranged from eleven years to thirteen years, four months. The children in the older mental age group used more prepositions than the younger group and were generally older by chronological age as well. Therefore, the effects of chronological age on the number of prepositions expressed by the EMR subjects cannot be accurately estimated, for the variable of mental age was not controlled. 
Besides examining the number or quantity of prepositions expressed, it is also interesting to evaluate which specific prepositions were used by each group of EMR and normal subjects. 'Generally, it was found at given mental age levels, performance between the groups was remarkably similar. As depicted in. Table III, these prepositions generally were the same for the two groups at given age levels. These results would tend to support a quantitative rather than a qualitative difference in performance. The EMR group appears to demonstrate a "developmental lag" in usage of prepositions rather than a disordered usage, i.e., the EMR group used the same prepositions as children of normal intelligence but appeared to learn and express them at a slower rate. There was also agreement between the two groups with regard to those prepositions not used. None of the children used "along," and it was noted at mentalage-six, both groups scored poorly on the more abstract prepositions "along," "about," and "of." Generally these results agree with Menyuk's (1971) contention that prepositions involving place are acquired first; those related to manner, next; and lastly, those referring to time.

It is interesting to note, "at" was expressed by at least 50 percent of both groups at mental-age-six, but not at mental-age-eight for either group. This could perhaps be explained by the tendency of the older groups to be short and "to the point" in their responses. For example, in response to the stimulus questions "Where would you buy this candy bar?" almost one-half of the children in each group simply responded with the noun "store." The frequent omission of "from" in the responses of the older group again could be attributed to the older children's limited verbalizations. Responses to the question, "Where do we get milk," was frequently "cow." Generally, however, omission of 
other prepositions decreased with mental age in both groups, leading to substitutions or correct usage of prepositions.

Out-of-class substitutions and substitutions in general decreased with advanced mental age. As evidenced by the great number of substitutions, many prepositions are interchangeable with other prepositions, e.g., "in back of" for "behind." Although few differences were found between the EMR and control groups, it was noted that the older children in the EMR group used "on" for "for," while the two control groups used "from" for "for" in response to "How did she get a new wátch?" It would appear "from" would be the more acceptable substitution, given the linguistic cues in the stimulus question. Results of this study agree with the findings of Grimm (1975), i.e., primary children replace complex prepositions with simpler ones. Examples at the eight year level included: "on/along," "on/against," "in back of/behind." The younger groups also used simpler prepositions in their substitutions.

Since performance between the experimental and control groups were so similar, comparison with results of preposition studies with normal populations gives added information. Hustead (1974) examined preposition usage of children from four to nine years; however, direct comparison with this investigation is not possible due to procedural differences. General comparison of results for prepositions expressed at ages six and eight between the two studies revealed some apparent discrepancies. First of all, the mean scores were higher in the earlier study. The average score for six year olds was 20.3 as compared to this study's six year old mean of 15. Eight year olds in the original study had a mean of 23.7 while the older group in this study averaged 17.8 prepositions. Additionally, while the same prepositions were used at 
each age, the percentage of children using each individual preposition was not as great as in the Hustead study. It was noted in the original. study, that 12 prepositions were used by all children at six years and 21 prepositions were used by the total number of children at eight years. Fewer prepositions were expressed by all the children of a group in this study. At age six, eight prepositions were used by all children and at age eight, twelve prepositions were used by all subjects. The prepositions used by all children at age six in the original study but not used by all children in the present study included: "across," "from," "of," and "on." At mental age eight, the total sample did not use these prepositions expressed by the Hustead (1974) subjects: "across," "at," "of," "to," "behind," "from," "by," "for," and "over." Explanations for reduced number of children expressing individual prepositions, lies partially in the increased number of subjects in this investigation ( 8 as compared to 6 in the original study) and variables in age criteria, in that this study used mental age rather than chronological age in the subject selection. Additionally, the HEPT does not include the prepositions "before," "beside," or "toward," which were tested on the EPT, and adds the prepositions "in front," "down," and "along." Therefore, in essence the tests are different in both scope and order, and this may have affected performance.

The variable of manner of presentation must also be considered. In Hustead's original study (EPT), the subjects were instructed to "fill-in" the missing prepositions when the examiner snapped her fingers. In using the HEPT, the pause-snap was eliminated and replaced with a question format. Occasionally a pause-fill-in was tacked onto the end of a sentence. It is possible the question format is the more 
difficult. No instructions were given to fill in any missing words, prior to testing as they were in the original study. Perhaps preliminary instruction of this sort would increase understanding of the task. Re-examination of the stimulus questions and cues is in order. 


\section{CHAPTER V}

SUMMARY AND IMPLICATIONS

\section{Summary}

The importance of successful usage of prepositions to the social, communicative, and academic achievement of the school age child has been documented in the 1iterature. Information on language skills of educable mentally retarded (EMR) children is of special concern because they represent the sub-group of mentally deficient individuals most likely to interact and participate in academic settings and community Iife.

The purpose of this study was to investigate which of 26 prepositions are acquired expressively by educable mentally retarded children. This study was designed to determine if there was a significant difference between the number of prepositions expressed by an EMR sample and those expressed by normals of similar mental age, and if the same prepositions were used by the two groups at given mental ages. The correlation between chronological age and the number of prepositions expressed by the EMR population was also investigated.

Thirty-two subjects in two mental age groupings participated in this study. At mental age six years ( \pm three months), eight EMR subjects and eight normals were selected. Eight individuals also comprised both groups at mental age eight ( \pm three months). The Hustead 
Expressive Preposition Test, (HEPT) (Hustead, 1978) was administered to all subjects.

Results showed no statistically significant differences between the EMR and normal groups at either mental age in the number of prepositions expressed, i.e., the EMR students generally were found to express the same number of prepositions as normals of similar mental ages. A moderate correlation between chronological age and the number of prepositions expressed by the EMR subjects was evident, suggesting experience and maturation could be related to the number of prepositions expressed; however, this relationship could be attributed in part to the older mental age of the children of older chronological age.

Comparison of the prepositions used by both groups at mental ages six and eight revealed more similarities than differences. Generally, the same prepositions were used by the subjects in the control and EMR groups at each mental age. Prepositions were found to develop similarly in number and type for both groups. Results of this study thus tend to indicate a "developmental lag" in usage of prepositions rather than a qualitative or disordered development.

\section{Implications}

\section{$\underline{\text { Clinic }}$}

From the results of this investigation, it is evident EMR children at mental ages six and eight years use the same number and type of prepositions as normals of similar mental ages. This suggests similar ordering of preposition development for the two groups. Prepositions, thus, could be taught to EMR children in the same order and scope as for normal children, commensurate to mental age of the EMR group. 
Since many prepositions are interchangeable with other prepositions, clinicians should consider accepting some substitutions. However, while it is important to teach the concept underlying an individual preposition, it is equally important to teach appropriate choice of prepositions in relation to linguistic cues as well. Usage of prepositions in relation to syntactic cues demonstrates language usage sophistication.

It is this investigator's opinion that the HEPT is a useful instrument for evaluating, in depth, expressive preposition usage. It is currently being standardized on a wide age range of children. When more normative data has been gathered, the HEPT will be of great clinical value in appraisal of language skills and subsequent formulation of appropriate language programs.

\section{$\underline{\text { Research }}$}

Due to the small number of subjects in this study (eight), findings that EMR children express similar prepositions as normals of matched mental age cannot be unequivocally generalized to all age levels. Implications for research comparing performance at other mental ages is indicated. A larger population could also yield more information about the wider range of variability in number of prepositions expressed by the EMR group. Research at lower levels of retardation is also needed to assist the structuring of language programs for those with varying degrees of limited intellectual functioning.

Although the relationship of chronological age with the number of prepositions expressed was discussed, it was not the focus of research. 
Future studies could explore this relationship more effectively by controlling the variable of mental age.

Additional research regarding the method of instruction of prepositions is also needed. Although this study revealed similar prepositions were used by both groups, it is not known if they learn the prepositions in the same manner. Research tends to indicate teaching the same prepositions as those expressed by normals, but more information is needed to determine how to instruct them.

It is also recognized that performance in this test is restricted to usage in a limited environment in response to specific questions. Additional studies could evaluate spontaneous usage and development of prepositions. 


\section{A SELECTED BIBLIOGRAPHY}

BAKER, T., and Dudrey, M., Developmental Age Study. Portland, Oregon: Special Education, Portland Public Schools (1968).

BERIETER, C., and Engelmann, S., Teaching Disadvantaged Children in the Preschool. Englewood Cliffs: Prentice-Hall, Inc. (1966).

BIBEY, M.L., A Rationale of Speech Therapy for Mentally Deficient Children. Training School Bulletin, 47, 17-27 (1951).

BLOUNT, W.R., Concept Usage Research With the Mentally Retarded. Psychological Bulletin, 69, 281-294 (1967).

BLOUNT, W.R., Retardate and Non-Retardate Concept Usage Performance: Abstraction Ability, Number of Referents and Item Familiarity. Institute of Exceptional Children and Adults, Papers and-Reports, Volume 1, Number 5 (1970).

BOEHM, A.E., Boehm Test of Basic Concepts. New York: Psychological Group (1969).

BOYD, R., Commend Made in Personal Communication, January 1, 1978.

BROWN, R., How Shall A Thing Be Called? Psychological Review, 65, 18-21 (1958).

BROWN, R., Social Psychology. New York: The Free Press (1965).

BROWN, R., A First Language: The Early Stages. Cambridge: Harvard University Press. (1973).

BROWN, R., and Bellugi, U., Three Processes in the Child's Acquisition of Syntax. In E. Lenneberg (Ed.) New Directions in the Study of Language. Cambridge: MIT Press (1964).

BROWN, R., and Berko, J., Word Association and The Acquisition of Grammar. Child Development, 31, 1-14 (1960).

BUIUM, N., Rynders, J., and Turnure, J., Early Maternal Linguistic Environment of Normal and Down's Syndrome Language Learning Children. Am. J. of Mental Deficiency, 79, 52-58 (1974).

CARRoLL, J.B., Language and Thought. Englewood Cliffs: Prentice-Hall, Inc., (1964). 
CAZDEN, C.B., The Hunt for the Independent Variable. In R. Huxley and E. Ingram (Eds.), Language Acquisition Models and Methods. London (1971) as cited in H. Grimm, On the Child's Acquisition of Semantic Structure Underlying the Wordfield of Prepositions. Language and Speech, 18, 97-119 (1975).

CLARK, E.V., On the Acquisition of the Meaning of "Before" and "After". J. of Verbal Learning and Verbal Behavior, 10, 266-275 (1971).

CLARK, H.H., Space, Time, Semantics, and the Child. In T.E. Moore (Ed.) Cognitive Development and the Acquisition of Language. New York: Academic Press (1973).

CORNWALL, J.B., Development of Language, Abstraction and Numerical Concept Formation in Down's Syndrome Children. Am. J. of Mental Deficiency, 79, 179-190 (1974).

CRABTREE, M., Houston Test for Language Development. Houston: Houston Test Co., (1958).

DANZER, V.A., Gerber, M.F., and Lyons, T.M., Daber.on. Portland, Oregon: Daberon Research (1972).

DELP, H.A., and Smeets, P.M., Language Assessment of Mental Retardates. Training School Bulletin, 70, 30-32 (1973).

DEWEY, G., Relative Frequency of English Speech Sounds. Cambridge: Harvard University Press (1923).

ERWIN-TRIPP, S., Language Acquisition and Communicative Choice. Standford: Standford University Press (1973).

FRANKENBURG, W.K., and Dodds, J.B., Denver Developmental Screening Test. Boulder: University of Colorado Medical Center (1967).

FRENCH, N.R., Carter, C.W., Jr., and Koenig, W., Jr., Words and Sounds of Telephone Conversations. Bell System Technical Journal, 9, 290-310 (19:30).

FRIEDMAN, W.J., and Seely, P.B., The Child's Acquisition of Spatial and Temporal Word Meanings. Child Development, 47, 1103-1108 (1976).

FRIES, C., American English Grammar. New York: Appleton-Century-Crofts Inc. (1940) as cited in A.H. Streng, Syntax, Speech, and Hearing. New York: Grune and Stratton (1972).

FRIES, C., The Structure of English. New York: Harcourt, Brace and World (1952).

GENS, G.W., The Speech Pathologist Looks at the Mentally Retarded Child. Training School Bulletin, 47, 236-239 (1951). 
GLEASON, H.A., Jr. An Introduction to Descriptive Linguistics. Revised Edition, New York: Holt, Rinehart, and Winston (1961) as cited in R. Brown, A First Language: The Early Stages. Cambridge: Harvard University Press (1973).

GRIMM, H., On the Child's Acquisition of Semantic Structure Underlying the Wordfield of Prepositions. Language and Speech, 18, 97-119 (1975).

GROSSMAN, H.J., (ED.) Manual on Terminology and Classification in Mental Retardation. American Association on Mental Deficiency, Special Publication Series No. 2(1973) as cited in J.M. Kaufman, Mental Retardation: Introduction and Personal Perspectives. Columbus: Charles E. Merrill Pub. Co. (1975).

HARRISON, R.H., Budoff, M., and Greenberg, G., Differences between EMR and Non-Retarded Children in Fluency and Quality of Verbal Associations. Am. J. Mental Deficiency, 79, 583-591 (19.75).

HECKEL, A.J., Chronological Age, Mental Age, and Socioeconomic Status Variance in Expressive Preposition Acquisition of Young Children. Unpublished Master's Thesis, Portland State University (1975).

HEDRICK, D. and Prather, E., Sequenced Inventory of Communication Deve1opment. Seattle: University of Washington and Child Development and Mental Retardation Center (1970).

HENDERSON,; L.J. Increasing Descriptive Language Skills in Educable Mentally Retarded Students. Mental Retardation, 9, 13-16 (1971).

HIMELSTEIN, P., The Slosson Intelligence Test. In O.K. Buros, (Ed.), The Seventh Mental Measurements Yearbook, Volume 1. New York: The Gayphon Press (1972).

HUSTEAD, G., Age, Intelligence, and Socioeconomic Status Variance in Preposition Acquisition by Children. Unpublished Master's Thesis, Portland State University (1974).

HUSTEAD, G., Hustead Expressive Preposition Test. Unpublished (1978).

JESPERSON, O., Language: Its Nature, Development, and Origin. New York: The MacMillan Company (1969).

JOHNSON, H.L., The Meaning of "Before" and "After" for Preschool Chi1dren. J. of Experimental Child Psychology, 19, 88-99 (1975).

JONES, L.V., Goodman, M.F., and Wepman, J.M., The Classification of Parts of Speech for Characterization of Aphasia. Language and Speech, 6, 91-108 (1963). 
JONGEWORD, P.A., A Validity Study of the Slossan Intelligence Test for Use with Educable Mentally Retarded Students. J. School Psychology, 7, 59-63 (1969).

JORDAN, T.E., The Mentally Retarded, Second Edition. Columbus: Charles E. Merrill Books, Inc., (1966).

JORDAN, T.E., Language and Mental Retardation: A Review of the Literature. In R.L. Scheifelbusch, R.H. Copeland, and J.O. Smith (Eds.), Language and Mental Retardation: Empirical and Conceptual Considerations. New York: Holt, Rinehart and Winston, Inc. (1967).

KARLIN, I.W., and Strazzula, M., Speech and Language Problems of Mentally Retarded Children. J. Speech and Hearing Dis., 17, 286-294 (1952).

KEANE, V.E., The Incidence of Speech and Language Problems in the Mentally Retarded. Mental Retardation, 10, 3-5 (1972).

KIRK, S.A., Education of Exceptional Children. Boston: Houghton Mifflin Co., (1972).

LACKNER, J.R., A Developmental Study of Language Behavior in Retarded Children. Neuropsychologia, 6, 301-320 (1968).

LEE, L., Brain Damage and the Power of Abstracting. ETC, 16, 154-162 (1959).

LENNEBERG, E., Nichols, J., and Rosberger, E., Primitive States of Language Development in Mongolism. Dis Comm., 42, 119-137 (1964).

LEWIN, K., A Dynamic Theory of Personality. New York: McGraw-Hill (1935) as cited in 0. Spreen, Language Functions in Mental Retardation: A Review, Part II: Language in Higher Level Performance. Am. J. of Mental Deficiency, 70, 351-363 (1965).

LILLYWHITE, H., Doctor's Manual of Speech Disorders. The J. of Am. Medical Association, 168, 850-858 (1958).

LOVELL, K., and Bradbury, B., The Learning of English Morphology in Educationally Subnormal Special School Children. Am. J. of Mental Deficiency, 71, 608-615 (1967).

MCCARTHY, J.J., Research on the Linguistic Problems of the Mentally Retarded Mental Retardation Abstracts, 2, 3-27 (1964).

McNEIL, The Acquisition of Language. New York: Harper and Row (1970).

MECHAM, M.J., Jex, J.L., and Jones, J.D., Utah Test of Language Development. Salt Lake City: Communication Research Associates Inc., (1969). 
MENYUK, P., Comparison of Grammar of Children with Functionally Deviant and Normal Speech. J.. Speech Hearing Res., 7, 109-121 (1964).

MENYUK, P., Sentences Children Use. Cambridge: The MIT Press (1969).

MENYUK, P., The Acquisition and Development of Language. Englewood Cliffs: Prentice-Hal1 (1971).

MOLLOY, J.S., Teaching the Retarded Child to Talk. New York: The John Day Co., (1961).

MONTAGUE, J.C., Jensen, P.J., and Wepman, J.M., Lexical Analysis of Institutionalized versus Non-Institutionalized Mentally Retarded. Training School Bulletin, 70, 160-166 (1973).

NAREMORE, R.C., and Dever, R.B., Language Performange of Educable Mentally Retarded and Normal Children at Five Age Levels. J. Speech and Hearing Res., 18, 82-95 (1975).

NEWFIELD, M., and Schlanger, B., The Acquisition of Engilsh Morphology by Normal and Educable Mentally Retarded Children. J. Speech and Hearing Res., 11, 693-706 (1968).

OGLAND, V.S., Language Behavior of EMR Children. Mental Retardation, 10, 30-32 (1972).

PALERMO, D., and Jenkins, J.J., Changes in Word Association of Fourth and Fifth Grade Children from 1916 to 1961. J. Verbal Learning and Verbal Behavior, 44, 180-187 (1965).

PIERCE, J.E., A Statistical Study of Grammar and Lexicon in Turkish and Sahptin (K1ikitat). International J. of Am. Linguistics, 23, 96-103 (1963).

PIERCE, J.E., The Morphemes of English: Unbound Minor Morphemes. Linguistics: An International Review, 47, 41-73 (1969).

P.L. 94-142, Education For All Handicapped Children Act, 1975.

ROSENBERG, S., Problems of Language Development in the Retarded. In H.C. Haywood (Ed.) Social-Cultural Aspects of Mental Retardation. New York: Appleton-Century Crofts (1970).

SCHIEFELBUSCH, R.L., Language Functions of Retarded Children. Folia Phoniatrica, 21, 129-144 (1969).

SCHIEFELBUSCH, R.L., Copeland, R.H., and Smith, J.O. (Eds.), Language and Mental Retardation: Empirical and Conceptual Considerations. New York: Holt, Rinehart and Winston, Inc. (1967).

SCHLANGER, B., Speech Examination of Institutionalized Mentally Handicapped Children. J. Speech Hearing Dis., 18, 339-349 (1953). 
SCOFIELD, P., Oral Language for the Educable Mentally Retarded. In M.V. Jones (Ed.) Language Development: The Key to Learning. Springfield: Charles C. Thomas, Pub., (1972).

SEMMEL, M., Barritt, L., Bennett, S., and Perfetti, A., A Grammatical Analysis of Word Associations of Educable Mentally Retarded and Normal Children. Am. J. Mental Deficiency, 72, 567-576 (1968).

SHIPLEY, E.R., Smith, C.S., and Gleitman, L.R., A Study in the Acquisition of Language: Free Responses to Commands. Language, 45, 322342 (1969).

SIEVERS, D.J., and Essa, S.H., Language Development in Institutionalized and Community Mentally Retarded Children. Am. J. of Mental Deficiency, $66,413-420$ (1961).

SLOBIN, D.I., Soviet Psycholinguistics. In D. O'Connor (Ed.) Present Day Russian Psychology: A Symposium by Seven Authors. Oxford, England: Pergamon Press (1966) as cited in P. Menyuk, The Acquisition and Development of Language. Englewood Cliffs:

Prentice-Hall, Inc., (1971).

SLOSSON, R.L., Slosson Intelligence Test. New York: Slosson Educational Publications (1971).

SMITH, J.0., Speech and Language of the Retarded. In J. Rothstern (Ed.) Mental Retardation. San Francisco: Holt, Rinehart, and Winston $(1,971)$.

SPRADLIN, J.E., Language and Communication of Mental Defectives. In. N.R. E1lis (Ed.) Handbook of Mental Deficiency. McGraw-Hill Book Co., New York (1963).

SPREEN, O., Language Functions in Mental Redardation: A Review, Part I: Language Development, Types of Retardation, and Intelligence Level. Am. J. of Menta1 Deficiency, 69, 482-492 (1965).

STRAZZULA, M.M., Speech Problems of the Mongoloid Child. In T.E. Jordan (Ed.) Perspectives in Mental Retardation. Illinois: Southern Illinois University Press (1966).

STEPHENS, W.E., Category Usage of Normal and Subnormal Children on Three Types of Categories. Am. J. of Mental Deficiency, 71, 266-273 (1963).

STERN, C., and Stern, W., Die Kindersprache. Eine Psychologische und Sprachtheoretische Untersuchung (Darmstadt) (1965) as cited in H.H. Grimm, On the Child's Acquisition of Semantic Structure Underlying the Wordfield of Prepositions. Language and Speech, 18, 97-119 (1975).

STRENG, A., Syntax, Speech and Hearing. New York: Grune (1972). 
STREMEL, K., and Waryas, C., A Behaviora1-Psycholinguistic Approach to Language Training, ASHA Monographs, 18, 96-125 (1974).

UNIVERSITY OF OREGON MEDICAL SCHOOL, Crippled Children's Division. Language Manual, Portland (1958).

VOEGELIN, C.F., Meaning Correlation and Selection in Morphology-Syntax Paradigms. Bulletin of Institute of History and Philogy Academia Sinica, 29, 201 (1957).

WEBSTER'S Fourth New Collegiate Dictionary. Springfield, Massachusettes: G. and C. Merriam Co., (1961).

WERNER, H., and Kaplan, B., Symbol Formation: An Organismic-Developmental Approach to Language and the Expression of Thought. New York: John Wiley and Sons Corp. (1963).

WEWETZER, K.H., Das Hirngeschaedigte Kind. Stuttgart: Thieme (1959) as cited in 0. Spreen, Language Functions in Mental Retardation: Am. J. of Mental Deficiency, 69, 482-492 (1965).

WIIG, E.H., and Seme1, E.M., Language Disabilities in Children and Adolescents. Charles E. Merrill Publishing Co., (1976).

WILLIS, V.L., and Garrison, M., Spoken Language Ability fo EMR and Normal Adolescents. Psychological Reports, 26, 696-698 (1970).

YODER, D., and Miller, J.R., What We Know and What We May Do. In J.E. McClean, D.E. Yoder, and R.L. Schiefelbusch, (Eds.) Language Intervention with the Mentally Retarded. Baltimore: University Press (1971). 


\section{APPENDIX A}

\section{NORMATIVE DATA ON PREPOSITIONS}

\section{COMPREHENSION OF FOUR PREPOSITIONS \\ BY CHRONOLOGICAL AGE \\ (Crabtree, 1958)}

Prepositions tested: "on," "under," "in front of" and "behind"

24 months: Comprehends one of the prepositions.

30 months: Comprehends two of the prepositions.

36 months: Comprehends three of the prepositions.

48 months: Comprehends all four of the prepositions.

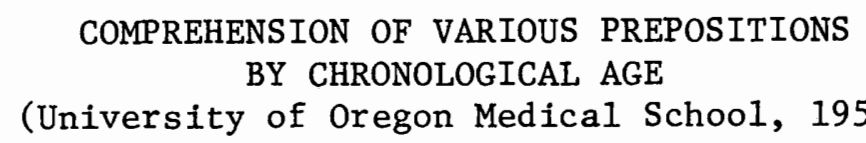

24 months: distinguishes "in," "under," and "beside" by correct response to commands.

30 months: responds to: "on," "under," "up," "down," "over there," and "by" when used in complete sentences.

36 months: responds to two related actions: "Run over to the chair and sit down."

42 months: follows commands: "Find the ball on the table and give it it to mother." Or: "Find the spoon in the box and give it to daddy."

48 months: comprehends: "Take the book from the table and give it to mother."

54 months: responds to: "Take the dolly to mother, open the door and bring in the baby buggy." 
COMPREHENSION AND EXPRESSION OF PREPOSITIONS

BY CHRONOLOGICAL AGE

(Baker and Dudrey, 1968)

\section{Months}

Expresses: Uses "after." Uses space words: "on," "up high," "in," "out," "fall down" and "turn around."

30 Months

Expresses: "up," "down," "way up," "in here," "under the table" and "around the table."

\section{Months}

Understands and uses 31 prepositions.

Expresses: "in the train," "over" and "around."

42 Months

Comprehends: "on," "in front of," "behind" and "under."

COMPREHENSION AND EXPRESSION OF PREPOSITIONS

BY CHRONOLOGICAL AGE

(Hedrick and Prather, 1970)

\section{Comprehension}

21-23 Months: "in."

27-29 Months: "on."

30-32 Months: "beside."

39-41 Months: "under."

\section{Expression}

30-32 Months: "in" and "on."

39-41 Months: "under" and "beside." 
PERCENTAGE OF PREPOSITIONS COMPREHENDED WHEN

VARIABLES OF AGE AND SOCIOECONOMIC

STATUS ARE CONSIDERED

(Frankenburg and Dodds, 1967)

Prepositions tested: "on," "under," "in front of," and "behind." Age when given per cent of population comprehended prepositions tested:

Comprehension of the prepositions, based on the total sample

\begin{tabular}{cccc}
\hline $25 \%$ & $50 \%$ & $75 \%$ & $90 \%$ \\
\hline 2.7 years & 3.1 years & 3.4 years & 4.5 years
\end{tabular}

Comprehension of the prepositions, based on occupation groups

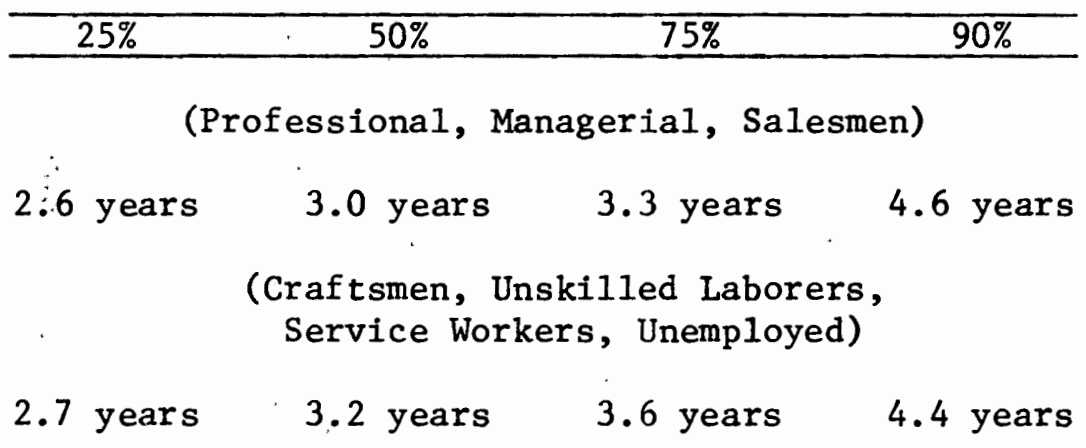




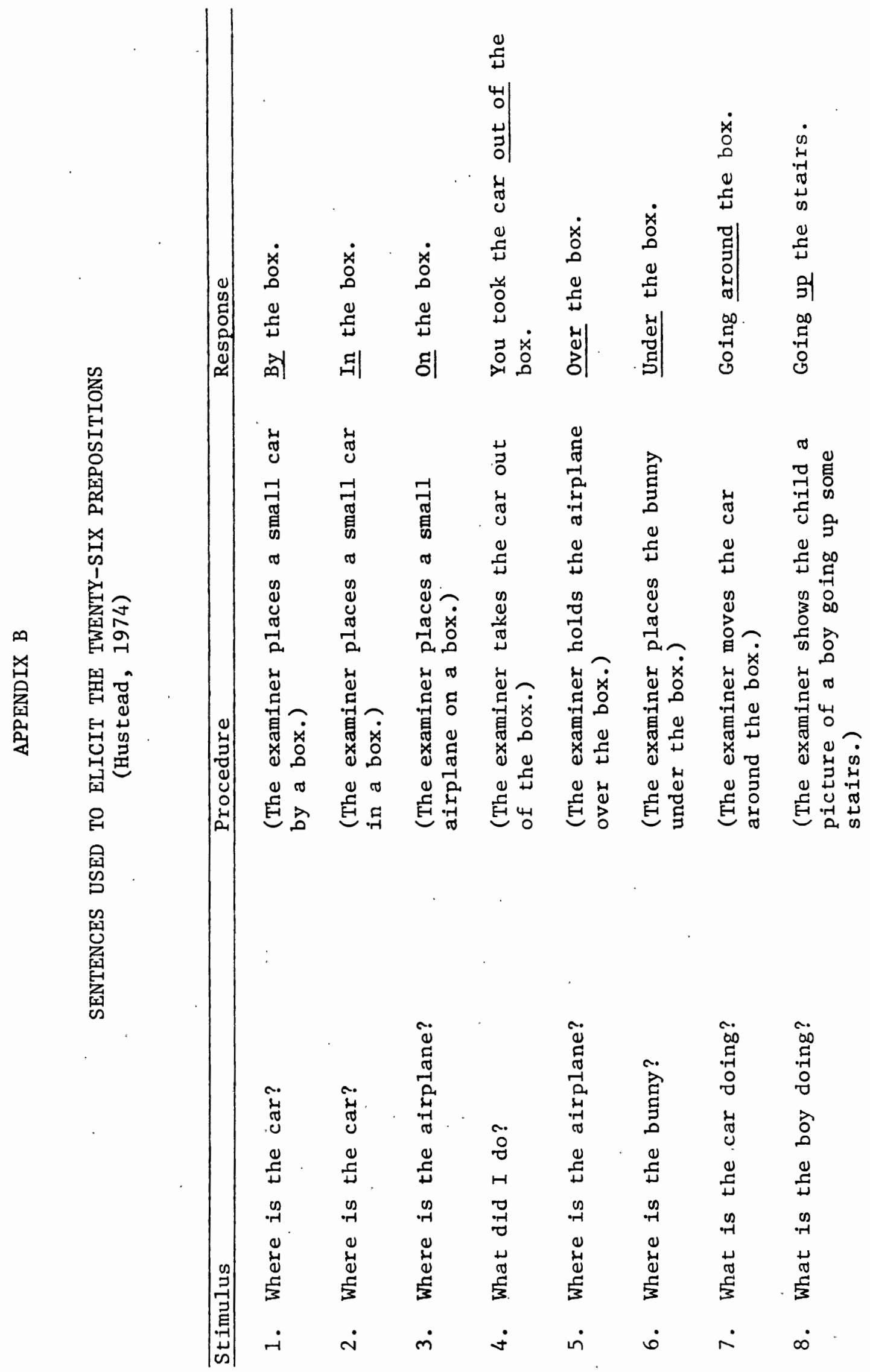




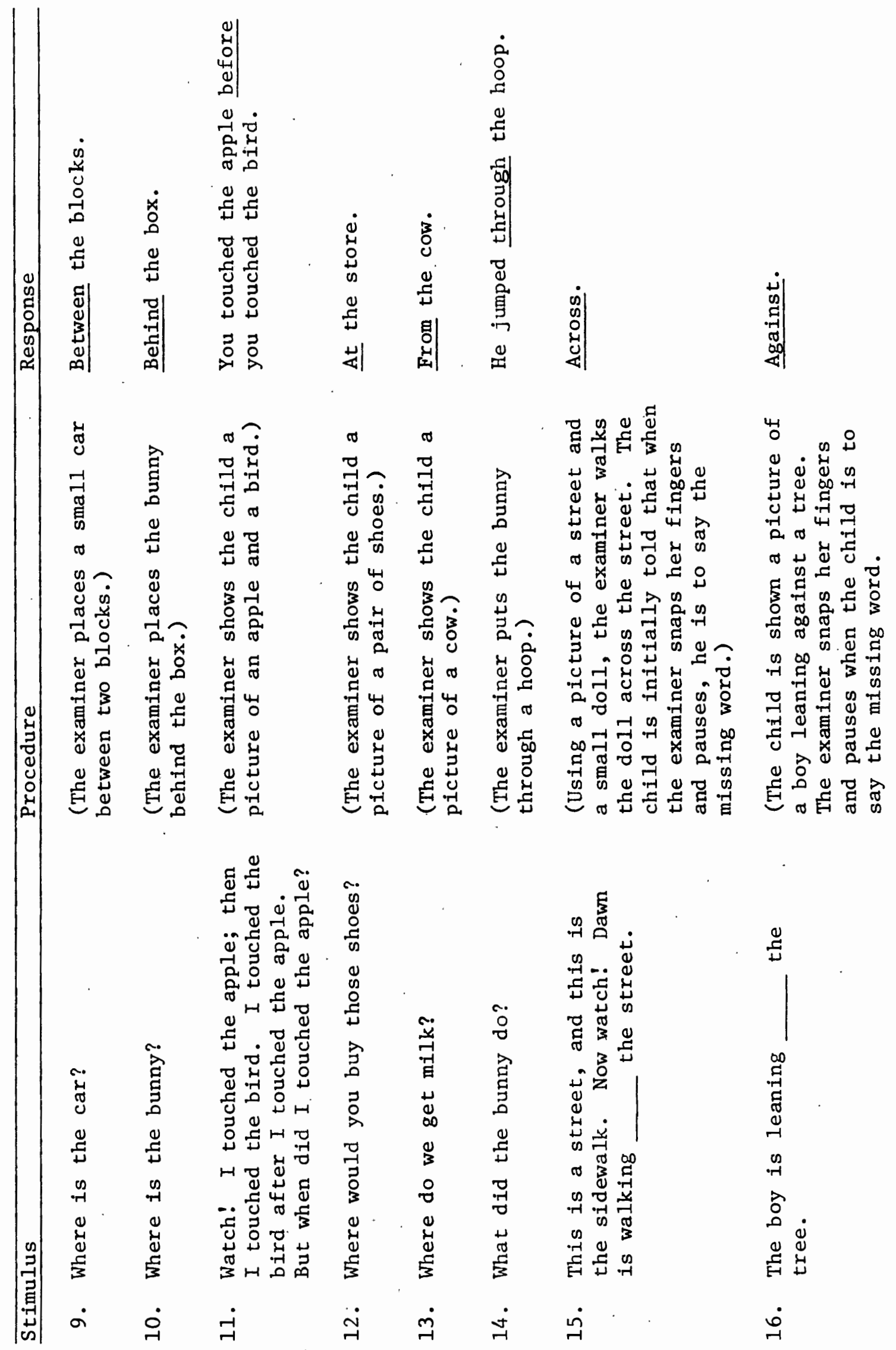




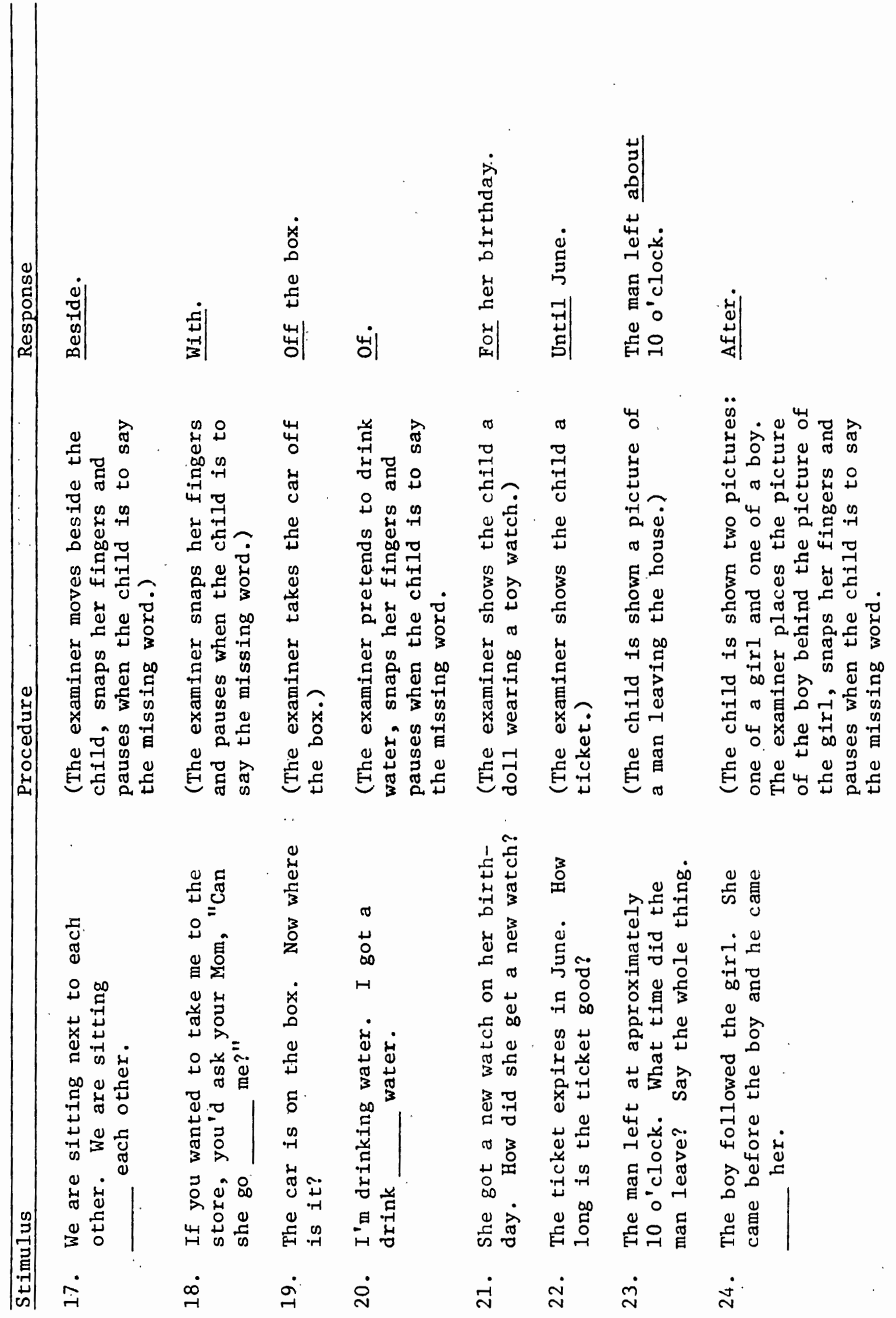




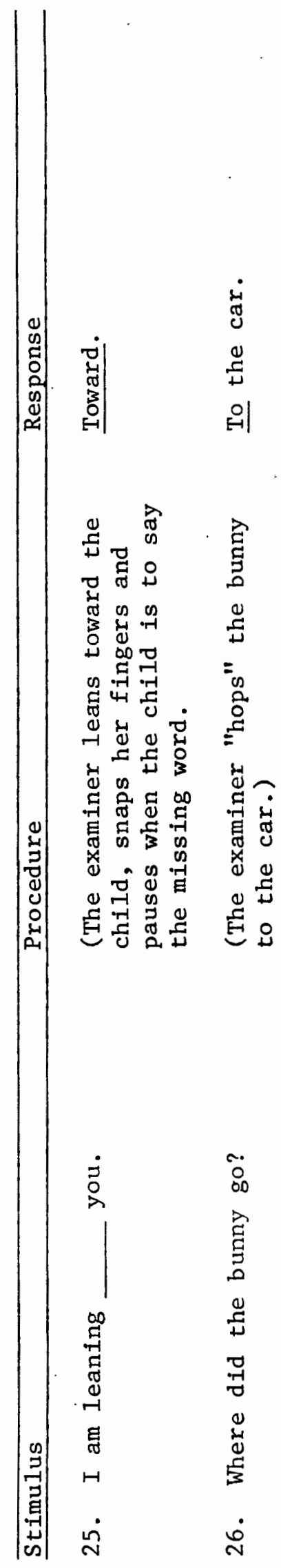




\section{APPENDIX C}

NUMBER OF CHILDREN AT EACH AGE LEVEL

THAT CORRECTLY EXPRESSED THE

INDIVIDUAL PREPOSITIONS

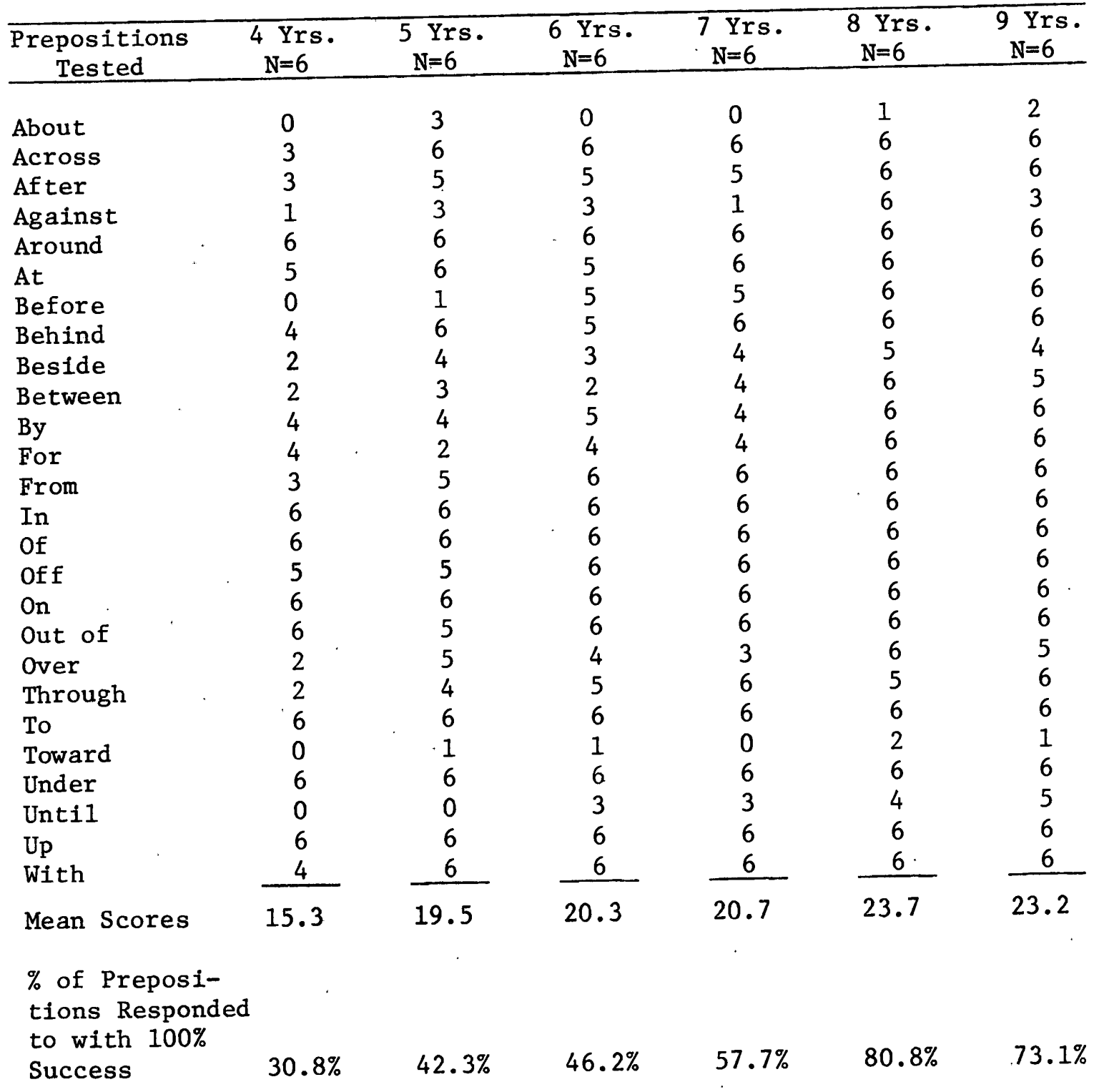




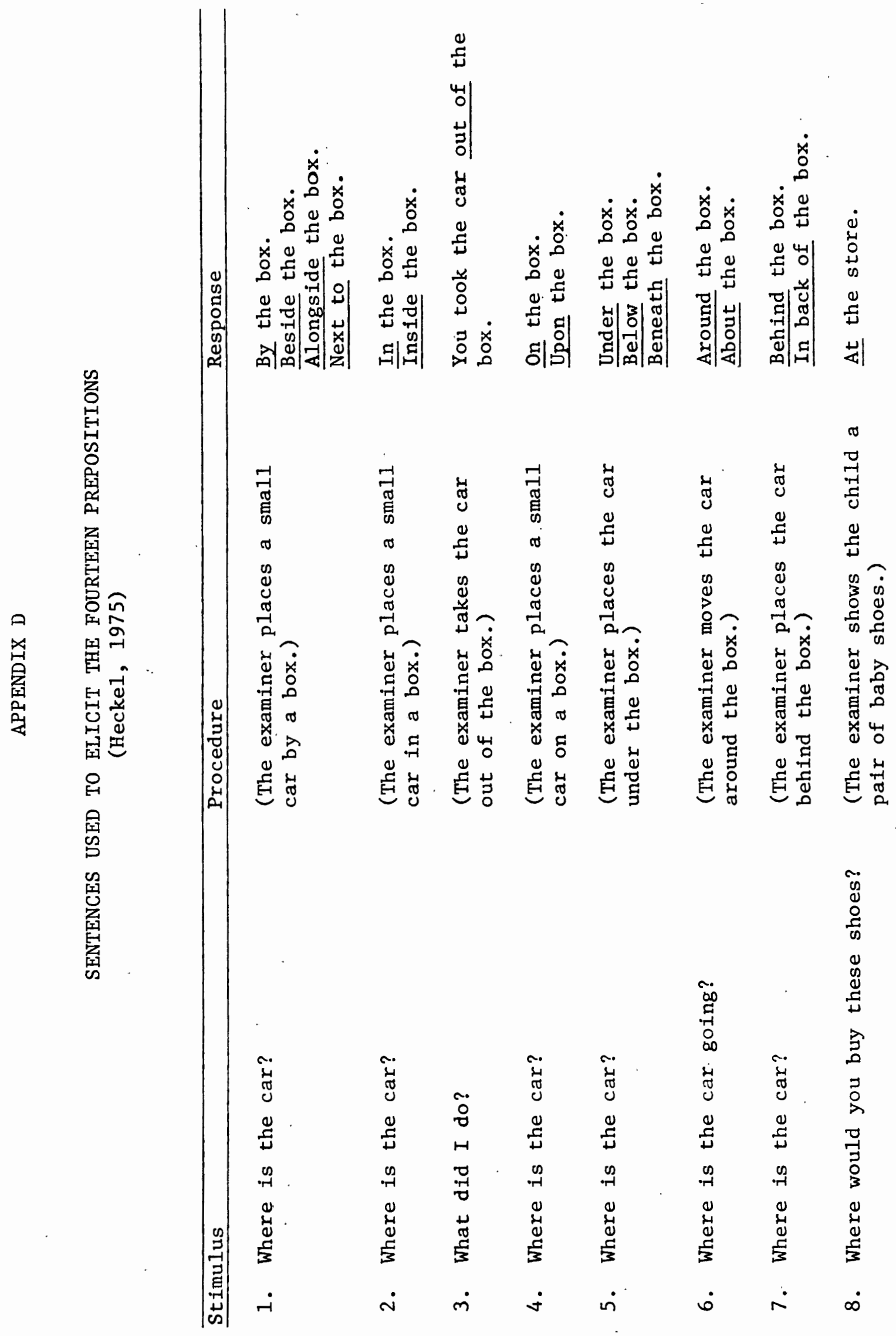




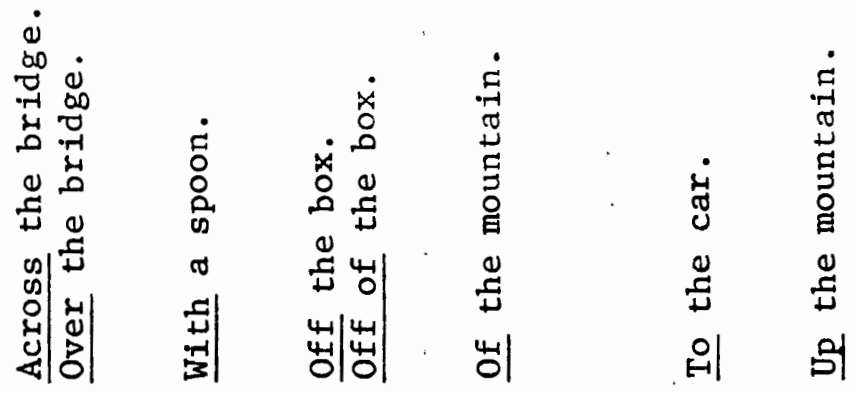

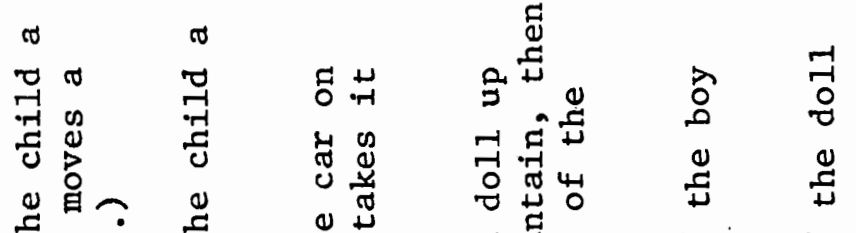

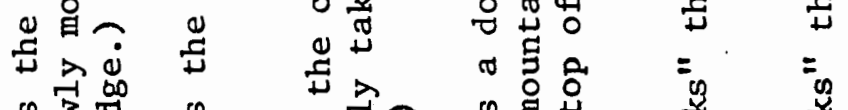

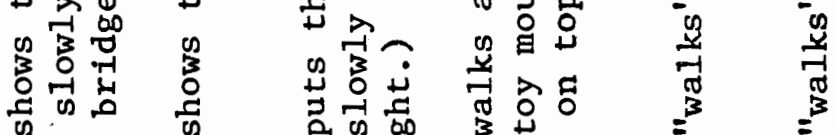

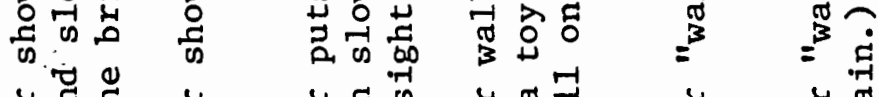

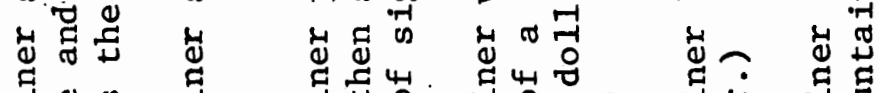

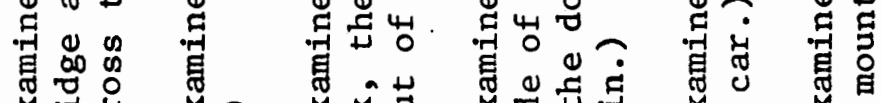

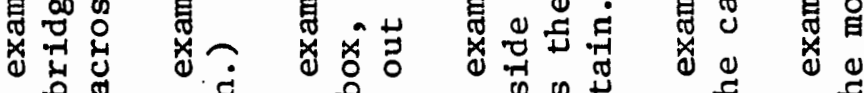

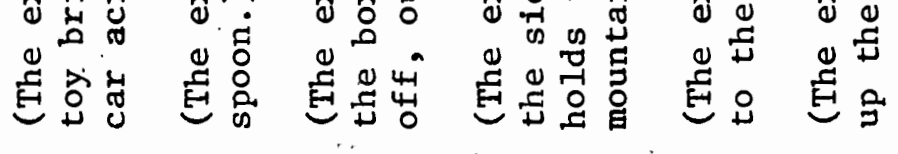

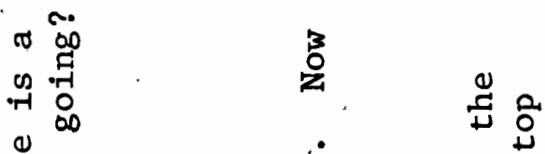

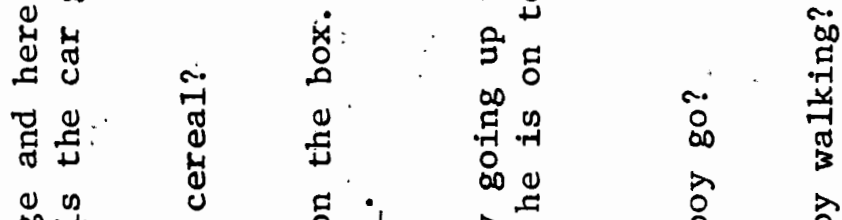

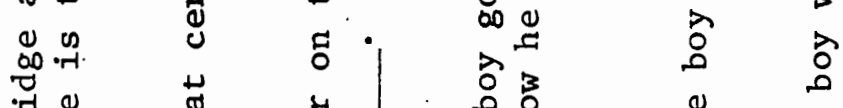

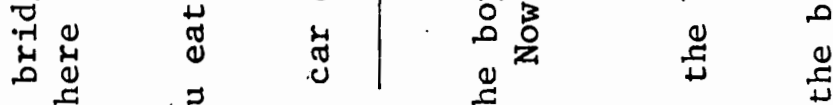

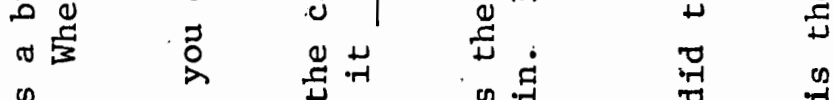



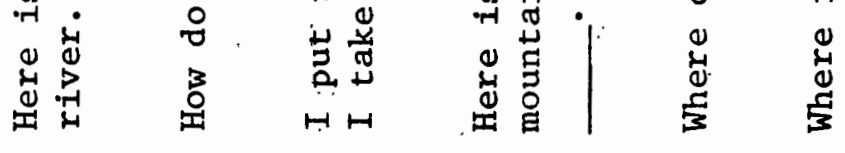

م $\dot{0}$ -

$\dot{\sim} \quad \dot{r} \quad \dot{ت}$ 


\section{APPENDIX E \\ NUMBER OF PREPOSITIONS CORRECTLY \\ EXPRESSED AT EACH AGE LEVEL \\ (Heckel, 1975)}

\begin{tabular}{|c|c|c|c|c|c|}
\hline $\begin{array}{c}\text { Preposition } \\
\text { Tested } \\
\end{array}$ & $\begin{array}{c}18 \text { Mos. } \\
\mathrm{N}=12\end{array}$ & $\begin{array}{c}2.4 \text { Mos. } \\
\mathrm{N}=12\end{array}$ & $\begin{array}{c}30 \text { Mos. } \\
\mathrm{N}=12\end{array}$ & $\begin{array}{c}36 \text { Mos. } \\
\mathrm{N}=1.2\end{array}$ & $\begin{array}{c}42 \text { Mos. } \\
\mathrm{N}=12\end{array}$ \\
\hline By & 0 & 0 & 2 & 0 & 5 \\
\hline In & 0 & 2 & 10 & 11 & 12 \\
\hline Out of & 0 & 0 & 4 & 6 & 8 \\
\hline On & 0 & 3 & 8 & 5 & 12 \\
\hline Under & 0 & 1 & 6 & 5 & 8 \\
\hline Around & 0 & 1 & 3 & 2 & 7 \\
\hline Behind & 0 & 0 & 0 & 1 & 0 \\
\hline At & 0 & 1 & 5 & 6 & 9 \\
\hline Across & 0 & 0 & 3 & 1 & 1 \\
\hline With & 0 & 0 & 4 & 3 & 10 \\
\hline off & 0 & 0 & 3 & 2 & 5 \\
\hline of & 0 & 1 & 5 & 2 & 9 \\
\hline To & 0 & 1 & 3 & 4 & 6 \\
\hline Up & 0 & 2 & 11 & 10 & 11 \\
\hline $\begin{array}{l}\text { Mean number } \\
\text { of correct } \\
\text { responses }\end{array}$ & .00 & 1.00 & 5.50 & 4.92 & 8.67 \\
\hline
\end{tabular}


APPENDIX F

PARENT PERMISSION FORM

\section{Dear Parent or Guardian:}

I am a graduate student in Speech Pathology at Portland State University, looking at the usage of prepositions by elementary students. In my study, I would like to include both students who receive special services outside of the classroom and those educated in the regular classroom without outside help. I've received permission from your principal, School in my study. , to engage students at

Elementary

As part of my study, I would like to give your child the following tests: a hearing screening, speech intelligibility measure, and the Slossin Intelligence Test as a measure of mental age. Subjects chosen will then be given the Expressive Preposition Test. In this test, they will be asked to explain where an object is located or describe some action by the examiner. All tests will be completed in one sitting and should take about thirty minutes maximum. I will administer all tests to the children.

No names will be used in the written results of this study. There has been much research on language skills in recent years, but we perhaps know the least about those who need the most help. From this study, it is hoped information can be gained to help plan language programs for these children.

I am requesting permission for your child to participate in the project outlined above. Please send the signed form below back to his/her teacher as soon as possible. If you have any further questions or concerns you may contact me at $229-3606$ or 229-3533.

Thank you for your cooperation.

Sincerely,

Marie Deon Shope

Graduate Student

Speech and Hearing Sciences

Portland State University 
DATE :

I

HEREBY PERMIT MY CHILD,

TO PARTICIPATE IN THIS STUDY.

MY CHILD'S BIRTHDATE: 


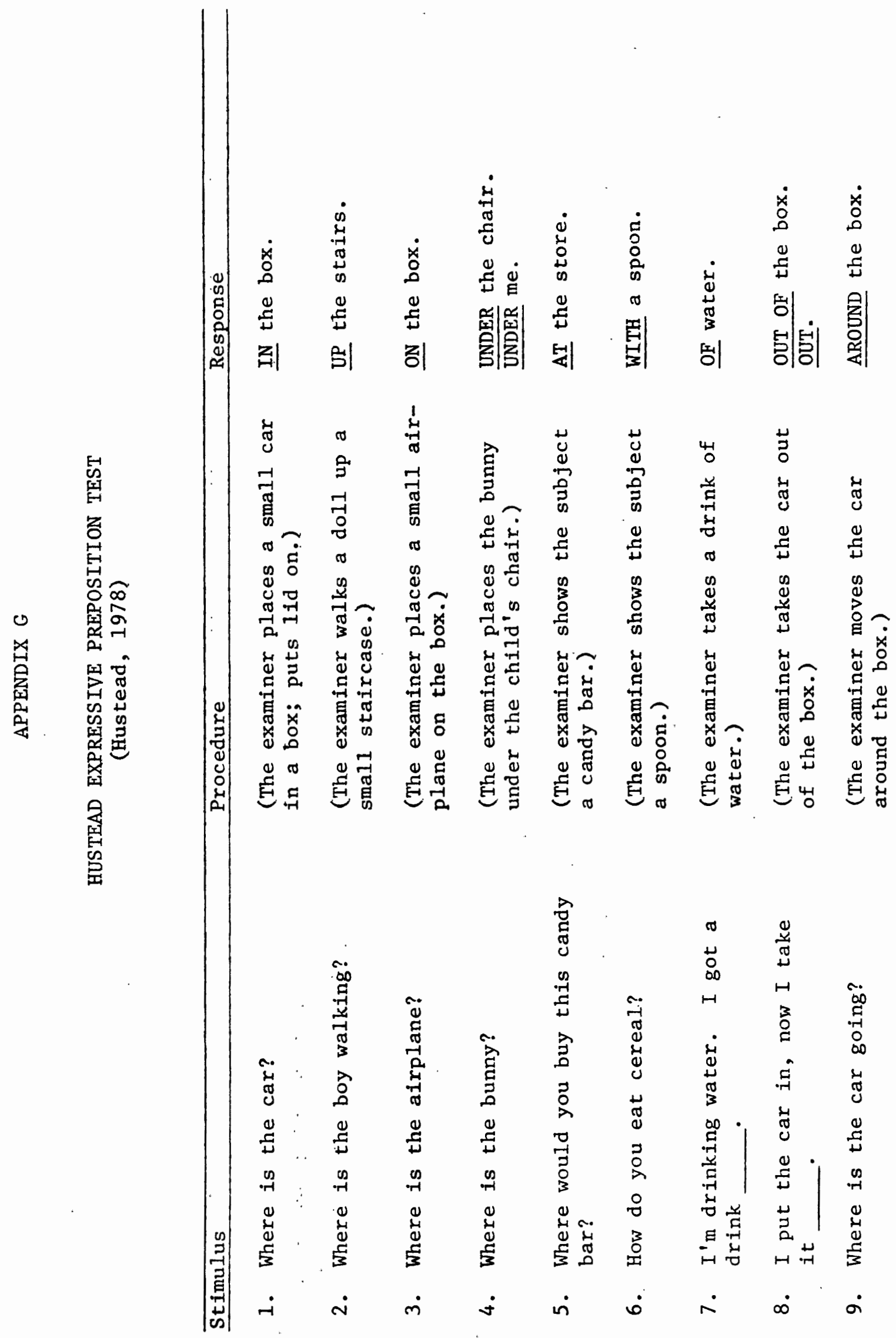




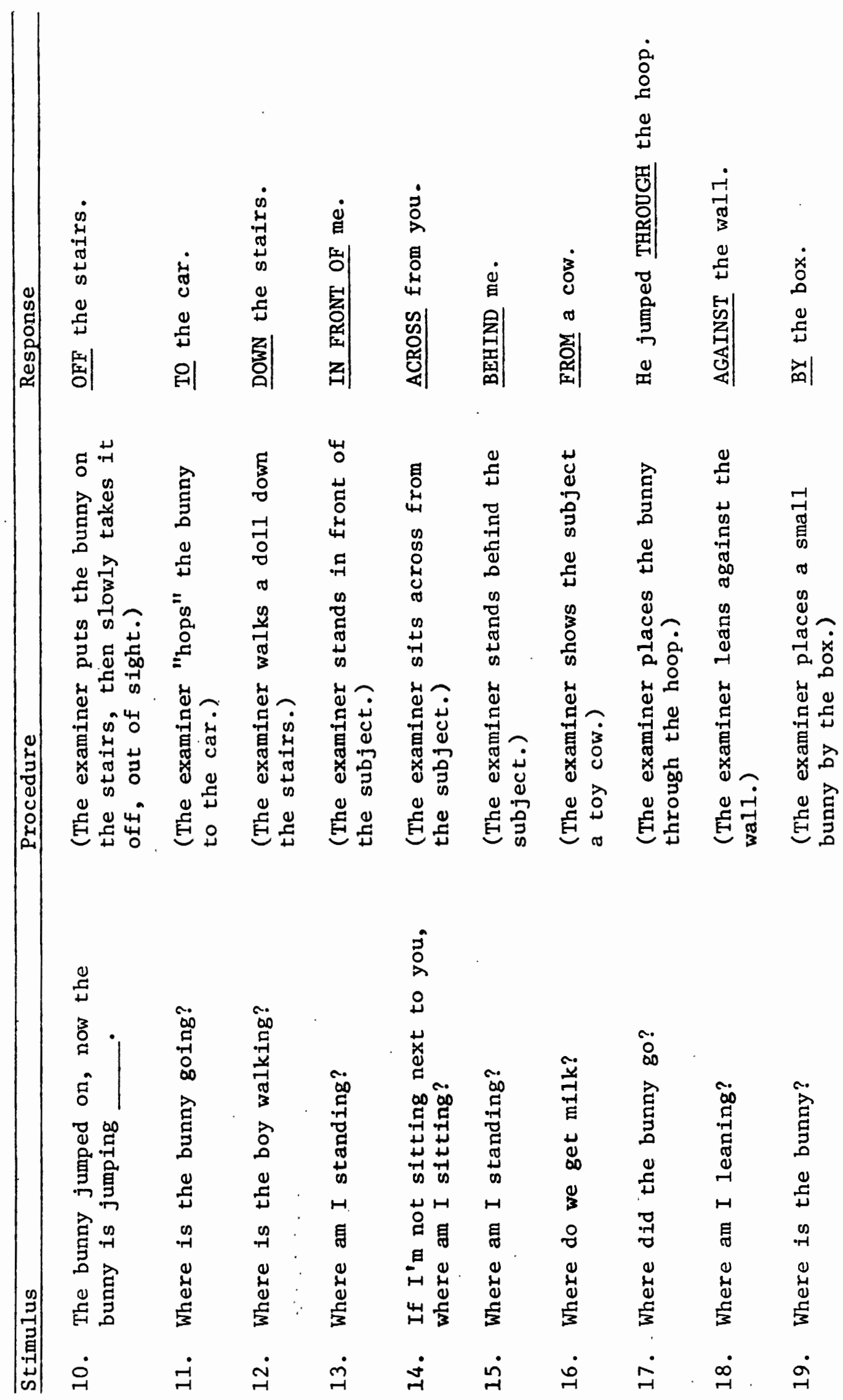




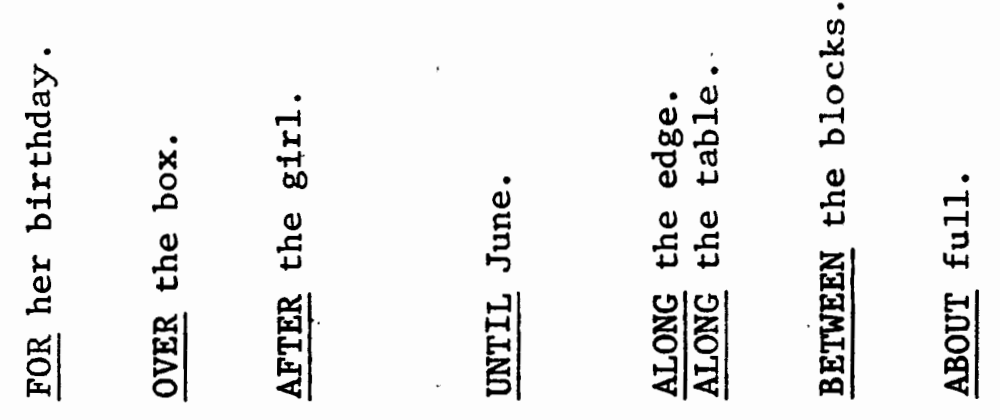

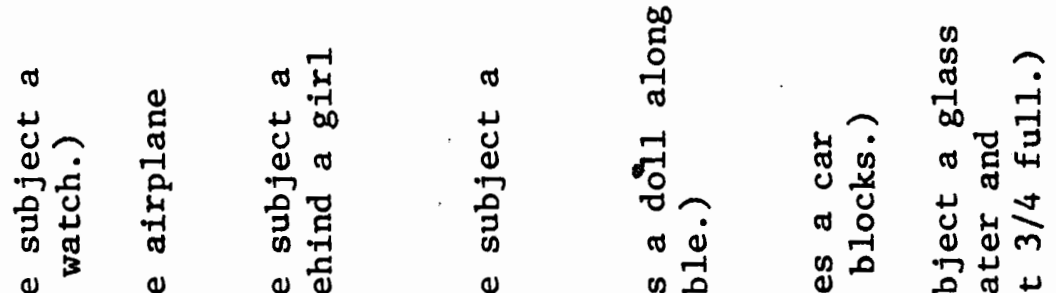

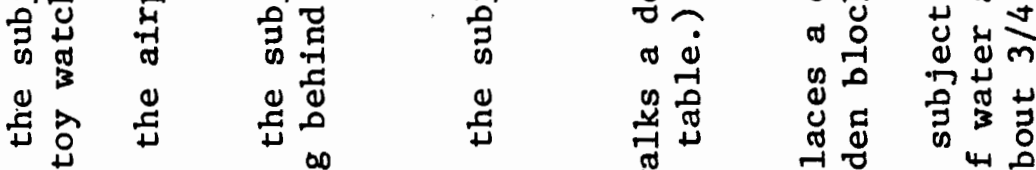

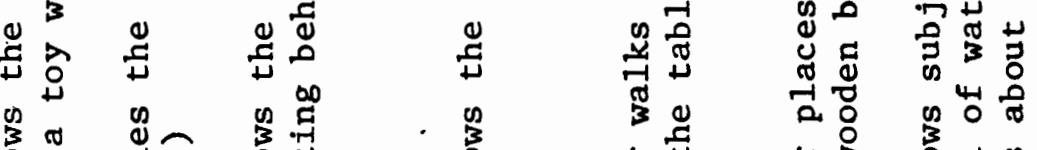

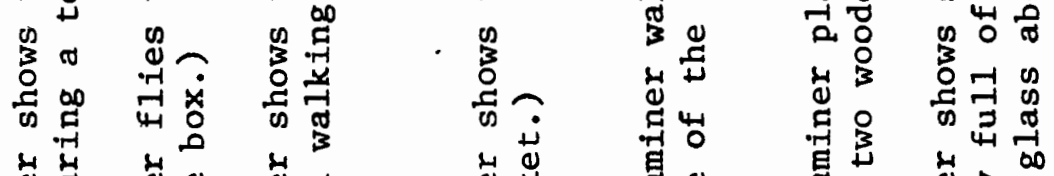

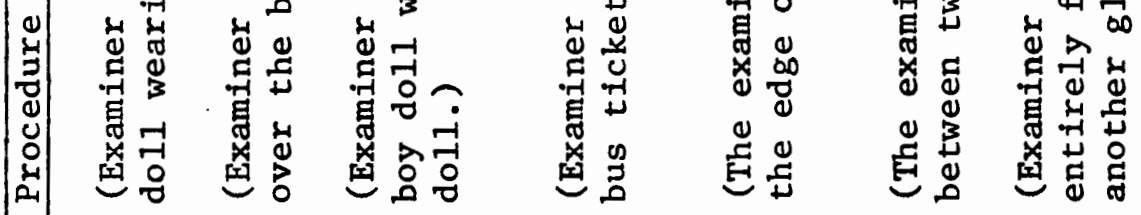




胥苛

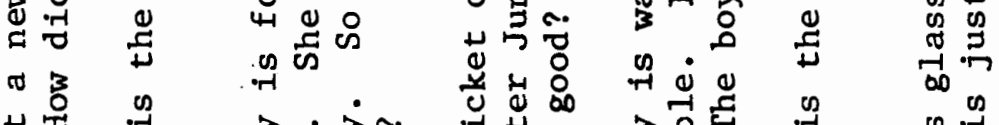



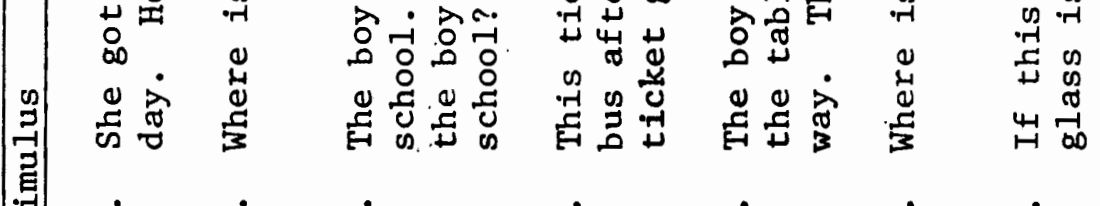

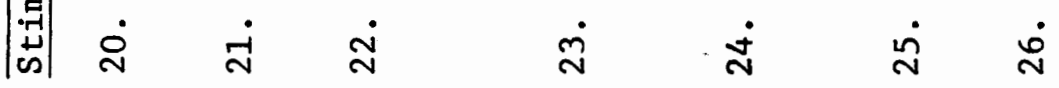






